\title{
COVID-19: A DOENÇA DOS ESPAÇOS DE FLUXOS
}

\section{Sonia Aguiar* \\ Universidade Federal de Sergipe}

Resumo: 0 objetivo deste ensaio é chamar a atenção para as possíveis rotas da propagação do novo coronavírus, desde a sua chegada ao Brasil (em um momento incerto por um portador não identificado) até o seu crescente e muito desigual espraiamento pelo território nacional, dos bairros nobres para as periferias das cidades e das capitais para o interior. Identificar a difusão de doenças no tempo e no espaço é uma das vertentes das pesquisas da geografia no campo da saúde, assim como informar o público sobre as ocorrências territorialmente diferenciadas dessa difusão é uma das tarefas das geografias da comunicação. 0 texto arrisca um diálogo entre essas duas vertentes de estudos interdisciplinares, visando uma perspectiva espacial às diversas interpretações ora em disputa sobre a pandemia da COVID-19.

Palavras chave: pandemia; geografia da saúde; geografia da circulação; geografias da comunicação; espaços de fluxos.

\section{COVID-19: A DISEASE OF SPACES OF FLOW}

Abstract: This essay aims at draw attention to the possible routes for the spread of the new coronavirus, from its arrival in Brazil (at an uncertain time by an unidentified carrier) to its growing and very uneven spread across the national territory, from the noble neighborhoods to the peripheries of the cities and from the state capitals to the hinterlands. Identifying the spread of diseases in time and space is one of the aspects of geography research in the health field, as well as informing the public about the territorially differentiated occurrences of this diffusion is one of the tasks of the geographies of communication. This paper risks a dialogue between these two strands of interdisciplinary studies, seeking a spatial perspective to the different interpretations now in dispute about the pandemic of COVID-19.

Keywords: pandemic; health geography; circulation geography; communication geographies; flow spaces.

\section{COVID-!9: UNA ENFERMEDAD DE ESPACIOS DE FLUJOS}

Resumen: El propósito de este ensayo es llamar la atención sobre las posibles rutas para la propagación del nuevo coronavirus, desde su llegada a Brasil (en un momento incierto por un transportista no identificado) hasta su propagación creciente y muy desigual en todo el territorio nacional, desde los barrios nobles hasta las periferias de las ciudades y desde las capitales de provincia hasta el interior. Identificar la propagación de enfermedades en el tiempo y el espacio es uno de los aspectos de la investigación geográfica en el campo de la salud, así como informar al público sobre los sucesos territorialmente diferentes de esta propagación es una de las tareas de las geografías de la comunicación. Este texto se arriesga a un diálogo entre estas dos líneas de estudios interdisciplinarios, apuntando desde una perspectiva espacial a las diferentes interpretaciones ahora en disputa sobre la pandemia de COVID-19.

Palabras-clave: pandemia; geografía de la salud; geografía de circulación; geografías de comunicación; espacios de flujo. 
Premissas

Desde meados do século passado, quando a Geografia Física perdeu a primazia para outras abordagens acerca do espaço, como a Humana, a Social, a Cultural, a Econômica, a aproximação entre geógrafos e outras disciplinas das Ciências Sociais, bem como de pesquisadores destas com a Geografia, tem resultado em áreas de investigação interdisciplinares inovadoras, como a Geografia da Saúde e as Geografias da Comunicação. Este ensaio arrisca um diálogo entre essas duas vertentes, visando a uma perspectiva espacial às diversas interpretações em disputa sobre a pandemia da Síndrome Respiratória Aguda Grave, tecnicamente nomeada Sars-Cov-2 ou COVID-19.

Mas a leitura espacial aqui proposta não é a de meros pontos fixos em um mapa, que assinalam casos suspeitos, casos confirmados, mortes registradas e doentes recuperados, e sim a de um olhar da "geografia do movimento", como diria Milton Santos. Ou da "geografia da circulação", tradicionalmente responsável pelos "estudos sobre o movimento de mercadorias, pessoas, ideias e informações" (Silva Junior, 2012). 0 objetivo é chamar a atenção para as possíveis rotas da propagação do vírus, desde a sua chegada ao Brasil (em um momento incerto por um portador não identificado) até o seu crescente e muito desigual espraiamento pelo território nacional.

Sem entrar no mérito das subnotificações, que são graves e até impeditivas para certas avaliações, os dados disponíveis em fontes públicas (de sites governamentais a portais de notícias) são suficientes para a observação desses movimentos e suas consequências para os diversos "desenhos" de propagação do vírus, evidenciados pelos variados mapas de dados temáticos disponíveis online.

Toma-se como premissa a própria dinâmica infecciosa dos vírus em relação a outros contaminantes, como as bactérias, por exemplo. Estas são microorganismos que contaminam pessoas localmente, por meio de contato com uma superfície infectada ou ingestão de alimento contaminado, mas a infecção dessa pessoa não será transmitida para outra com quem tiver contato. Já os vírus necessitam, obrigatoriamente, de um hospedeiro, preferencialmente humano, e são transmitidos tanto por contágio direto quanto por meio de um vetor (como o mosquito que transmite a dengue, a zica e a chicungunha), cada qual formando um elo na cadeia de propagação.

Logo, considerando que pessoas passam boa parte das suas vidas em movimento, os meios de transporte são um ambiente inevitável para a dinâmica da rede de contaminação. E desses, aviões são certamente aqueles capazes de transportar o vírus mais rapidament para locais diversos e bem longe da sua origem. Neste contexto, aeroportos são objetos geográficos não só porque ocupam lugares e exercem funções estratégicas nesses lugares, como também porque são estruturas fixas que desencadeiam fluxos de pessoas e mercadorias sobre diversos espaços, em direção outros lugares. É dessa "dialética entre a frequência a espessura dos movimentos" (Santos e Silveira, 2008, p.167) que nascem os conflitos entre os fluxos (das pessoas contaminadas por diversos territórios) e os fixos desta pandemia (centros de triagem, hospitais com leitos, UTIs e respiradores disponíveis, cemitérios, covas e crematórios para todos os corpos)

\section{Livre trânsito para contaminados sem sintomas}

Para um vírus poderoso como os da família corona a circulação é a alma do negócio e a velocidade, o seu modus operandi. Portanto, a questão não está apenas na aglomeração em espaços fixos, como shoppings, restaurantes e supermercados, mas sobretudo no rastro vão deixando em seus fluxos pelos espaços. Assim considerando que o "novo coronavírus" não é nativo do Brasil, suas principais portas de entrada só podem ter sido os aeroportos situados em capitais de estado com rotas de/para outros países. Ou seja, fluxos de passageiros vindos de todas as partes do mundo que em seguida transitaram entre as cidades do país (em alguns casos, com conexão em aeroportos regionais) e, ao se constatarem contaminados, desencadearam movimentos em busca de unidades de saúde para se atendimento em diferentes condições da doença.

Trata-se, assim, de uma doença dos espaços de fluxos, sujeita a variáveis de duração, extensão, escala e superposições (Santos, 2014, pp. 148-149). A duração diz respeito ao "lapso de tempo em que um dado evento, guardando suas características constitucionais, tem presença eficaz" (a curva epidemiológica, por exemplo). A extensão refere-se à amplitude do evento dentro de determinada escala geográfica. Mas, como adverte Milton Santos (2014, p.149), "os eventos não se dão isoladamente, mas em conjuntos sistêmicos (...) que são cada vez mais objetos de organização na sua instalação, no seu funcionamento e no respectivo controle de regulação". Logo, "há ações capazes de ter efeitos de abrangência mundial, no sentido de que num dado momento, sua eficácia se faz sentir além dos niveis local, regional numerosos situados em diversos países e continentes" (Santos, 2014, p.153), como as recomendações da OMS - Organização Mundial da Saúde sobre isolamento social, uso de máscaras, testagem massiva etc.

Um evento de escala planetária como esta pandemia está sujeito a superposições de amplitude e duração diversas, em seus diferentes recortes geográficos, ao mesmo tempo em que pode ter sua existência encurtada ou prolongada mediante dado recurso organizacional (isolamento vertical ou horizontal, flexibilização ou lockdown, testagem seletiva ou em massa). Essas superposições abrangem também a ação de eventos consecutivos ou simultâneos e seus impactos sobre as estruturas fixas disponíveis: contaminação assintomática ou com sintomas; contaminação importada ou transmissão comunitária; atendimento de casos leves ou internação em estado grave; mortes identificadas ou indefinidas; e o ciclo desses eventos que se reinicia continuamente.

É o que demonstram as evoluções da pandemia em diferentes unidades da federação (UFs) brasileira, exaustivamente divulgadas pelos meios de comunicação a partir de março de 2020, quando os números começaram a assustar. No início de abril, São Paulo, Rio de Janeiro, Ceará, Distrito Federal e Amazonas foram considerados pelo Ministério da Saúde como "a turma mais preocupante em todo o território nacional"', porque a disseminação corria o risco de entrar em um processo acelerado, de difícil controle. Naquele momento, essas cinco UFs concentravam $70 \%$ dos casos confirmados e quase $80 \%$ do total das mortes ocorridas no país por COVID-19. Mas os sinais dessa aceleração já vinham desde meados de março, quando SP, RJ e DF apareciam na dianteira de casos confirmados da doença, com média entre $70 \%$ e $75 \%$ do total do país, nas contas das respectivas secretarias estaduais de saúde ${ }^{2}$. 0 Ceará tinha, então, cinco notificações confirmadas (atrás de outros seis estados) e o Amazonas, apenas uma.

Em 18 de março, quando o Brasil ainda registrava 350 casos no painel da Universidade Johns Hopkins (eram 534 no painel do G1) e a China somava 81.102, a Itália já havia notificado 35.713 casos, contra 13.910 da Espanha, 7.661 da França e 7.323 dos EUA, para citar apenas alguns dos destinos mais frequentes dos passageiros brasileiros no exterior. No dia seguinte, a OMS divulgou um boletim informativo (Situation Report $59)$, no qual relatava a entrada de sete países de quatro 'Frase do então ministro da Saúde, Luiz Henrique Mandetta, em entrevista coletiva
em 04/04/2020. 2Todos os números de casos registrados/confirmados no Brasil citados neste
artigo foram consultados no painel de "Casos de coronavirus no Brasil e no mundo", atualizado diariamente pelo portal $G$ desde $21 / 0,0 / 20$, com dados das
secreteraias estaduais de saude. Os dados de outros paises foram consultados no
Coronavirus Resource Center da Johns Hopkins University and Medicine. regiões do mundo na lista de territórios com pessoas contaminadas.

Nesse dia, os casos confirmados ultrapassaram a casa dos 200 mil, o que indicava que o ritmo com que a doença estava se espalhando acelerou: enquanto o vírus havia levado três meses para contaminar 100 mil pessoas, a segunda centena de milhares de casos foi alcançada em apenas 12 dias. Onze dias depois, oito capitais brasileiras já haviam ultrapassado 100 casos confirmados em cada (ver Tabela 1). À exceção de Manaus, essas capitais fazem parte da lista dos 11 aeroportos brasileiros que movimentaram o maio número de passageiros em 2019, segundo dados da ANAC - Agência Nacional de Aviação Civil (Tabela 2).

Essa aceleração da curva de contaminação no mundo e no Brasil deveria ter sido suficiente para acender a luz amarela nas autoridades de saúde em relação aos fluxos de pessoas chegando da Europa e dos EUA. Contudo, mesmo com tanta gente circulando, as primeiras medidas de atenção à pandemia que se avizinhava não passaram de alertas genéricos sobre os sintomas da doença e cuidados de higiene. Nenhum tipo de barreira sanitária ou monitoramento dos históricos de viagem foi adotado nos três principais entroncamentos aéreos do país - Guarulhos (SP), Galeão (RJ) e Brasília (DF) -, como revelam diversos relatos divulgados por passageiros recém-chegados.

Fluxos de pessoas formam as redes de contágio

Em busca dessa relação entre voos e a pandemia, um grupo de pesquisadores em Ecologia da Universidade de São Paulo (USP), liderados pelo biólogo Paulo Roberto Guimarães $\mathrm{Jr}$, realizou um experimento com base nas teorias das redes de interação entre espécies e na "centralidade de Katz" Epidemias têm duas dinâmicas de propagação bem
distintas. Em uma localidade, o contato entre eessoas
determina determina como uma doença se espalha em um
cidade. Porém, entre cidades, a dinâmica depende também do movimento de pessoas por grandes
distancias. Nada permite o movimento de grandes quantidades de pessoas por grandes distâncias tanto quanto os avioes. Logo, of fluxo de pessoas em avioees
por diferentes aeroportos pode determinar comm uma epidemia se propogagada entre paises e dentro de (GIACOBELLI e GUIMARÃES JR, 2020).

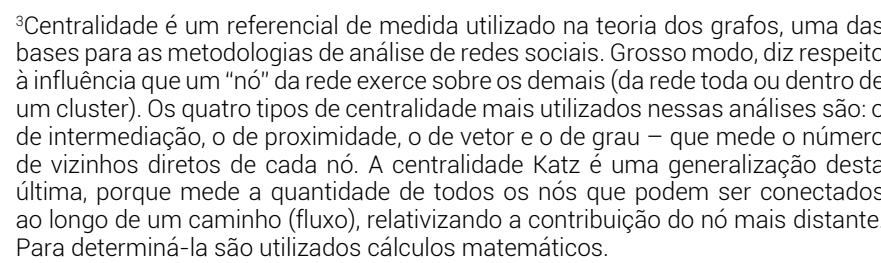


Figura 1: Dinâmica da propagação por fluxos aéreos no Brasil

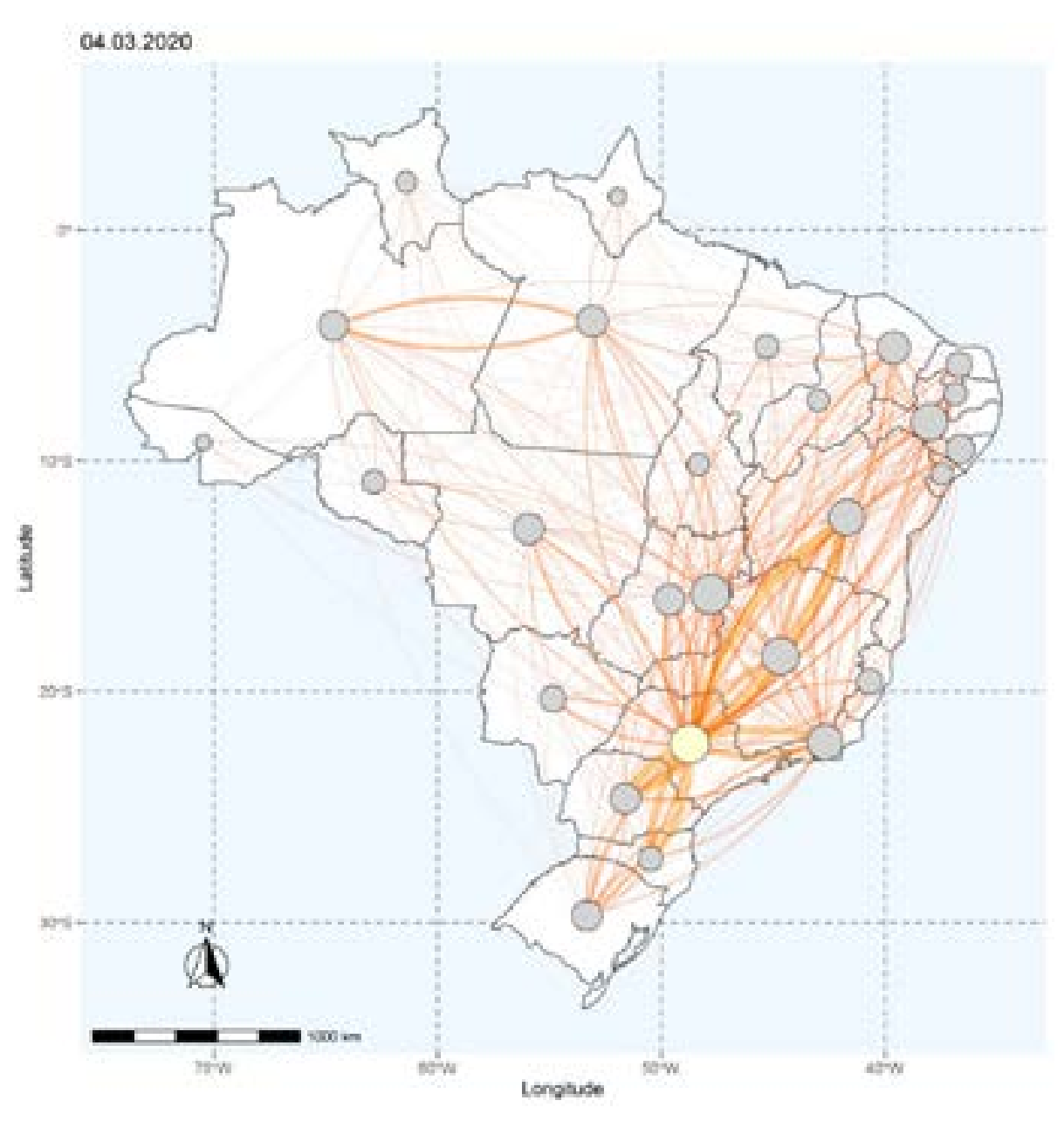

Guimarães Lab/ Observatório Covid-19 (Acesso em: 22/03/20)

Para o experimento, os pesquisadores compilaram os dados da quantidade de voos diretos entre aeroportos brasileiros, fornecidos pela ANAC para 2019, e agruparam os fluxos aéreos por estados. Criaram, assim, a representação gráfica de uma rede (grafo), "na qual pontos representam estados brasileiros e as setas indicam a intensidade de voos saindo de um estado e chegando em outro (ponta da seta)". Com o auxílio de um software específico, os pesquisadores produziram um grafo para cada dia dessa movimentação (de 4 a 22 de março) e os superpuseram para montar uma representação animada (Figura 1), que permite simular a dinâmica de propagação da pandemia entre os estados. Contudo, essa simulação restringe-se à circulação do vírus no território nacional e não explica como ele chegou ao Brasil e se disseminou de forma tão rápida, mas concentrada em determinados estados.
Histórico de viagem: uma variável relevante para o monitoramento local e regional

Segundo o Anuário Estatístico da ANAC 2018 (o mais recente disponível em abril de 2020), no mercado doméstico, os terminais aeroviários com maio movimentação de voos em 2018 foram os de Guarulhos (12,2\% do total do país), Congonhas (10,8\%), Brasília ( $8 \%)$, Confins $(5,8 \%)$ e Campinas $(5,8 \%)$. Logo, os três principais aeroportos comerciais do estado de SP foram responsáveis por quase $29 \%$ de todo o tráfego aéreo brasileiro em 2018. Ao todo foram transportados 93,6 milhões de passageiros em 816 mil voos (conforme o Painel de Indicadores do Transporte Aéreo 2018) Já na distribuição regional de passageiros pagos transportados no mercado doméstico em 2018 a região Sudeste ficou com $49,3 \%$ do totat com mais de 46 Sudeste ficou com $49,3 \%$ do total, com mais de 46 milhões de passageiros, seguida pela Região Nordeste,
com 17 milhões (18,8\%), e pelo Centro-Oeste (13,5\%), com 12,6 milhões. Os aeroportos da Região Norte foram os que menos processaram passageiros em 2018, com um pouco mais de 5 milhões do total $(5,4 \%)$

A grandeza e a distribuição regional desses números (ainda que defasados) têm correspondência nas diferenciações do território brasileiro, entre o que Milton Santosidentificava comoa"regiãoconcentrada",formada pelas áreas com maior densidade de "meio técnicocientífico-informacional" e fluidez de comunicações (materiais e imateriais), e o "resto" do país. Esta categorização tem resistido a inúmeras variáveis de fixos e fluxos que se apliquem ao território naciona (indústria, comércio, meios de comunicação, transportes, educação, saúde, bens culturais, equipamentos urbanos etc.), e persistiu nos dados iniciais sobre a pandemia de COVID-19. Porém, a partir da segunda quinzena de março de 2020, os registros de contaminação no Ceará e no Amazonas indicavam que os fluxos se impuseram aos fixos e criaram novos desenhos regionais na rede nacional de propagação do novo coronavírus.

Tabela 1: Capitais brasileiras com maior número de casos confirmados (2020)

\begin{tabular}{|l|l|l|l|}
\hline Capital (UF) & $\begin{array}{l}\text { Total de casos } \\
\text { em 29/03/20 }\end{array}$ & $\begin{array}{l}\text { Total de casos } \\
\text { em 07/04/20 }\end{array}$ & $\begin{array}{l}\text { Variação } \\
\text { (9 dias) }\end{array}$ \\
\hline São Paulo (SP) & 899 & 3.754 & $\times \mathbf{4 , 1 7}$ \\
\hline Rio de Janeiro (RJ) & 517 & 1.110 & $\times 2,14$ \\
\hline Fortaleza (CE) & 339 & 990 & $\times 2,92$ \\
\hline Brasília (DF) & 298 & 485 & $\times 1,62$ \\
\hline Belo Horizonte (MG) & 143 & 275 & $\times 1,92$ \\
\hline Porto Alegre (RS) & 143 & 260 & $\times 1,81$ \\
\hline Manaus (AM) & 131 & $\mathbf{5 6 0}$ & $\times \mathbf{4 , 2 7}$ \\
\hline Salvador (BA) & 103 & 264 & $\times 2,56$ \\
\hline Total: & 2.573 & 7.698 & $\times 2,99$ \\
\hline Brasil & $\mathbf{4 . 3 3 6}$ & $\mathbf{1 4 . 0 7 6}$ & $\times \mathbf{3 , 2 4}$ \\
\hline
\end{tabular}

Fonte: Elaboração própria com base no Painel Coronavírus do G1/ Bem Estar. Em 07/04/2020, Manaus passou à frente de Brasilia, com um aumento exponencial e Salvador e Porto Alegre trocaram de posiçoes (para $7^{\mathrm{a}} \mathrm{e} 8^{\mathrm{a}}$, respectivamente).

A Tabela 1 mostra como as propagações ocorreram em velocidades diferentes no mesmo período, nas capitais com maior concentração de casos confirmados, com crescimento exponencial em Manaus, a um ritmo maior que o da capital paulista - as duas únicas acima da média nacional. Mostra também que essas oito capitais concentravam mais da metade dos casos do país até o início de abril. Já a Tabela 2 mostra o ranking dos aeroportos brasileiros com maior volume diário de passageiros em 2018, cujas sedes coincidem, em boa maior número de casos de COVID-19 confirmados até a finalização deste artigo. Os dois estados que sediam os cinco aeroportos mais movimentados do país são justamente os que ocuparam o topo da lista da pandemia desde os primeiros casos notificados no país. Na sequência vinham Brasília (que durante semanas alternou com Fortaleza o terceiro e o quarto lugares nessa lista), Belo Horizonte, Porto Alegre e Salvador. 


\begin{tabular}{|l|l|l|}
\hline Aeroporto & $\begin{array}{l}\text { Passageiros } \\
\text { pagos }\end{array}$ & Cidade (UF) \\
\hline $\begin{array}{l}\text { Aeroporto Internacional de São Paulo- } \\
\text { Guarulhos }\end{array}$ & 42248207 & Guarulhos (SP) \\
\hline Aeroporto de São Paulo-Congonhas & 22281896 & São Paulo (SP) \\
\hline $\begin{array}{l}\text { Aeroporto Internacional Presidente Juscelino } \\
\text { Kubitschek }\end{array}$ & 16569442 & Brasília (DF) \\
\hline $\begin{array}{l}\text { Aeroporto Internacional Tom Jobim-Rio } \\
\text { Galeão }\end{array}$ & 13518783 & Rio de Janeiro (RJ) \\
\hline Aeroporto Internacional de Tancredo Neves & 10734359 & Confins/ Belo Horizonte (MG) \\
\hline Aeroporto Internacional de Viracopos & 10199171 & Campinas (SP) \\
\hline Aeroporto Santos Dumont & 8933777 & Rio de Janeiro (RJ) \\
\hline Aeroporto Internacional Gilberto Freyre & 8638608 & Recife-Guararapes (PE) \\
\hline Aeroporto Internacional Salgado Filho & 8106869 & Porto Alegre (RS) \\
\hline $\begin{array}{l}\text { Aeroporto Internacional Dep. Luís Eduardo } \\
\text { Magalhães }\end{array}$ & 7351020 & Salvador (BA) \\
\hline Aeroporto Internacional Pinto Martins & 7087627 & Fortaleza (CE) \\
\hline TOTAL: & 155.669 .759 & \\
\hline
\end{tabular}

Fonte: Elaboração própria com base no relatório Dados Estatísticos da ANAC (Consultado em 21 de março de 2020).

Os pontos fora da curva nessa comparação (em 07/04) eram: Campinas, que desde o início da pandemia manteve números baixos de casos notificados, se comparados com a sua população, estimada em 1.200 mil pessoas para 2019, e aos mais de 10 milhões de Viracoposi For recentes da COVID-19; e Manaus, que apesar de ser o $17^{\circ}$ no ranking em passageiros aéreos transportados, superou Brasília e alcançou o indesejado $4^{\circ}$ lugar na lista da COVID, com 560 casos em 7 de abril e 1.664 doze dias depois.

Apesar do aumento significativo de casos nessas três cidades, essas posições relativas se mantiveram até o fechamento deste artigo, em 19/04. Mas três capitais tiveram suas posições bastante alteradas (conforme Tabela 3). Recife, que ocupa $08^{\circ}$ lugar no ranking dos aeroportos, com mais de 8 milhões de passageiros, teve uma explosão de casos confirmados, em parte em função de uma política mais agressiva de testagens, subindo para logo atrás de Manaus. Já Salvador, que é $10^{a}$ no ranking aéreo, subiu uma posição no número de casos, enquanto Porto Alegre, que é $9^{a}$, caiu da $8^{a}$ para a $11^{\text {a }}$ posição em casos da COVID-19, em função da situação das demais. Das oito capitais selecionadas selecionadas para este ensaio, com base naquele alerta do Ministério da Saúde, São Paulo, Rio de Janeiro, Manaus e Salvador conseguiram reduzir a velocidade da contaminação na primeira quinzena de abril, enquanto Fortaleza, Brasília, Belo Horizonte e Porto Alegre tiveram o ritmo acelerado.

\begin{tabular}{|l|l|l|l|l|l|}
\hline Cidade (UF) & Rk aéreo & Rk Covid & $\begin{array}{l}\text { Casos em } \\
\mathbf{0 7 / 0 4}\end{array}$ & $\begin{array}{l}\text { Casos em } \\
\mathbf{1 9 / 0 4}\end{array}$ & $\begin{array}{l}\text { Variação } \\
\mathbf{1 2} \text { dias }\end{array}$ \\
\hline Guarulhos (SP) & 1 & $15^{\circ}$ & 74 & 305 & $\times 4,12$ \\
\hline São Paulo (SP) - Congonhas & 2 & $1^{\circ}$ & 3.754 & 9.428 & $\times 2,51$ \\
\hline Brasília (DF) & 3 & $8^{\circ}$ & 485 & 754 & $\times 1,55$ \\
\hline $\begin{array}{l}\text { Rio de Janeiro (RJ) - GIG + } \\
\text { SDU }\end{array}$ & $4 / 7$ & $2^{\circ}$ & 1.110 & 3.126 & $\times 2,81$ \\
\hline Belo Horizonte (MG) & 5 & $10^{\circ}$ & 275 & 420 & $\times 1,52$ \\
\hline Campinas (SP) & 6 & $30^{\circ}$ & 28 & 184 & $\times 6,67$ \\
\hline Recife (PE) & 8 & $5^{\circ}$ & 153 & 1.408 & $\times 9,20$ \\
\hline Porto Alegre (RS) & 9 & $11^{\circ}$ & 260 & 374 & $\times 1,43$ \\
\hline Salvador (BA) & 10 & $7^{\circ}$ & 264 & 761 & $\times 2,88$ \\
\hline Fortaleza (CE) & 11 & $3^{\circ}$ & 990 & 2.688 & $\times 2,71$ \\
\hline Manaus & 17 & $4^{\circ}$ & 560 & 1.664 & $\times 2,97$ \\
\hline
\end{tabular}

Fonte: Elaboração própria com base no Painel Coronavirus do G1/ Bem Estar em 19/04/20

Mas se nem todos os números batem, o que os fluxos de passageiros têm a ver com a disseminação do novo corona vírus no Brasil? A resposta é que nem tudo se explica apenas por variáveis quantitativas. Os mapas das rotas nacionais e, sobretudo, internacionais dos aeroportos situados nas oito capitais com maior incidência da do histórico de viagens no monitoramento dos percursos e dos ritmos da pandemia no Brasil, cujas variáveis locais e regionais também têm sido pouco consideradas pelo Ministério da Saúde (na contramão de governadores e prefeitos).

O painel Rio Covid19, produzido pelo DataRio, o portal de dados do órgão de planejamento urbano da Prefeitura carioca4, chegou a incluir um gráfico pizza com os percentuais do "histórico de deslocamento internacional" de pessoas suspeitas ou confirmadas de contaminação, associado a um mapa com a localização dos casos notificados na cidade. A representacão cartográfica indicava a dominância de casos nos bairros da Zona Sul, majoritariamente habitados pelas classes A e média alta (perfil de viajantes internacionais, a passeio ou a trabalho) e por onde também circulam muitos estrangeiros, devido à concentração da rede hoteleira. Posteriormente, contudo, esse dado foi excluído do painel, talvez devido ao alto percentual "sem informação" (26,3\%), o que gerava imprecisão no acompanhamento da dinâmica local da epidemia.

Em Sergipe, os primeiros cinco casos confirmados pela Secretaria estadual de Saúde, na primeira quinzen de março, foram de residentes da capital, Aracaju, com histórico de viagem: um casal vindo da Espanha, com conexão em Guarulhos; um homem com passagem recente por Brasília; uma mulher que veio dos EUA e teve contato lá com caso confirmado, e um homem que esteve com paciente da Covid-19 em São Paulo. Todos entraram imediatamente em isolamento domiciliar e passaram a ser monitorados pela Vigilância Sanitária Estadual, juntamente com os demais passageiros dos respectivos voos. Foi graças a esse procedimento que um sexto caso foi localizado na cidade de Propriá, a $101 \mathrm{~km}$ da capital. A partir do primeiro caso, o governo estadual passou a informar o histórico de viagens quando divulgava casos confirmados, mas abandonou a prática a partir da constatação do início da "contaminação comunitária".

Rotas do "novo coronavírus": do mundo para o Brasil

Quando se olha para os mapas das malhas de chegadas e partidas dos aeroportos com maior fluxo de passageiros do país, tendo em mãos os números de casos confirmados da COVID-19 nas respectivas capitais e regiões metropolitanas, a rede de propagação parece se movimentar sobre as representações cartográficas. Todas as rotas ${ }^{5}$ deixam clara a centralidade do aeroporto de Guarulhos (SP) como hub (entroncamento) dos voos nacionais, seguido do Galeão (RJ) e de Brasília (DF), e 
a dominância dos voos internacionais para o "Velho Continente" (Portugal,Espanha, Itália,FrançaeAlemanha) e para a Costa Leste dos Estados Unidos, especialmente Miami e Nova York. Ou seja, justamente os países que, à exceção de Portugal, alcançaram o topo do "ranking" da pandemia no mundo em março, desbancando a China no início de abril.

Mas o levantamento dos primeiros casos confirmados em cada estado ratifica a tendência apontada acima e nos faz lembrar que os fluxos dos aeroportos não dizem respeito apenas aos passageiros dos voos e tripulantes das aeronaves. Envolvem também os amigos e familiares que participam das chegadas e despedidas, bem como os trabalhadores fixos e prestadores de serviços eventuais que transitam pelos terminais. Tanto que, a partir do inicio de abril, os casos confirmados nas

Figura 2: Rotas do aeroporto internacional de Guarulhos (SP)

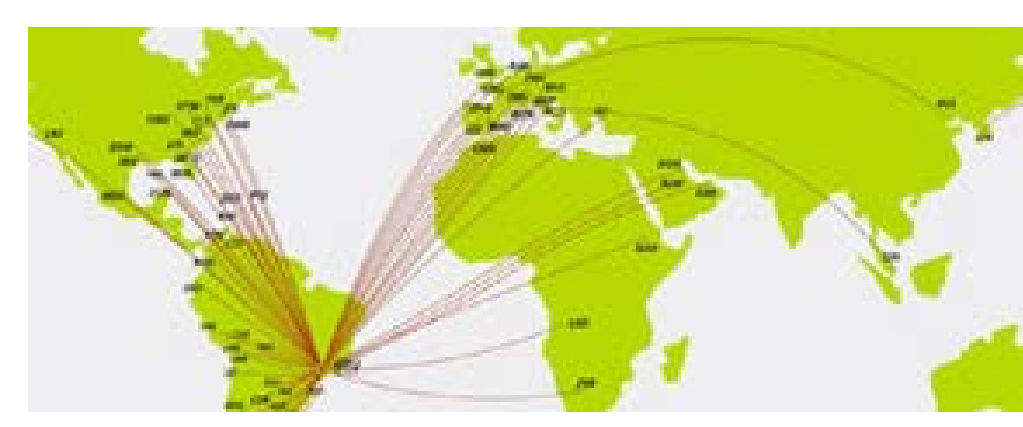

Fonte: Aeroporto Guarulhos-São Paulo (Acesso em: 09/04/20)

de/para quase todos os estados do Nordeste e os do Sul, além de Brasília e alguns estados do Norte e Centro Oeste.

Toda essa movimentação pelos três terminais do GRU permaneceu a pleno vapor entre 26 de fevereiro, quando o Ministério da Saúde confirmou o primeiro caso do novo coronavírus no Brasil, em São Paulo, e 17 de março, quando a GOL iniciou a suspensão progressiva de seus voos internacionais, seguindo decisão tomada dois dias antes nos EUA pela American Airlines. Quando os primeiros voos começaram a ser suspensos, o estado de SP tinha 164 doentes notificados em nove cidades todas na Região Metropolitana de São Paulo (RMSP), sendo $156(95 \%)$ na capital. A cidade de Guarulhos registrara, então, apenas um caso. Passados 23 dias (08/04), já eram 6.708 casos em 132 cidades paulistas, das quais 32 da RMSP, incluindo a capital, concentravam $76 \%$ dos casos registrados em todo o estado. A essa altura, Guarulhos tinha 74, número que pulou para 305 onze dias depois. cidades de Guarulhos e Campinas se multiplicaram, com mostrado na Tabela 3.

a) São Paulo, o epicentro de todos os fluxos no Brasil

Situado em uma das 39 cidades que compõem a Região Metropolitana da capital paulista, o Aeroporto Internacional de São Paulo/Guarulhos é o maior entroncamento aeroviário do Brasil e "o mais movimentado da América do Sul, com uma média de 40 milhões de usuários por ano" e capacidade instalada para 52 movimentos de aeronaves por hora (entre pousos e decolagens), segundo a GRU Airport, que administra 0 empreendimento desde 2012. As mais de 35 companhias aéreas que ali atuam operam 92 destinos, no Brasil e no exterior, abrangendo todos os continentes (Figura 2). Na

fluminense, que se tornaria a primeira pessoa no Estado a contrair a COVID-19, oficialmente, em 5 de março. Segundo reportagem da época (SATRIANO, 05/03/2020), a mulher esteve em Mirão, na Lombardio (uma das áreas onde a pandemia foi mais severa), com o marido, que não apresentou sintomas. Ambos e mais as pessoas próximas a eles no avião seriam monitoradas pelos órgãos estaduais de saúde. Naquele momento, casos

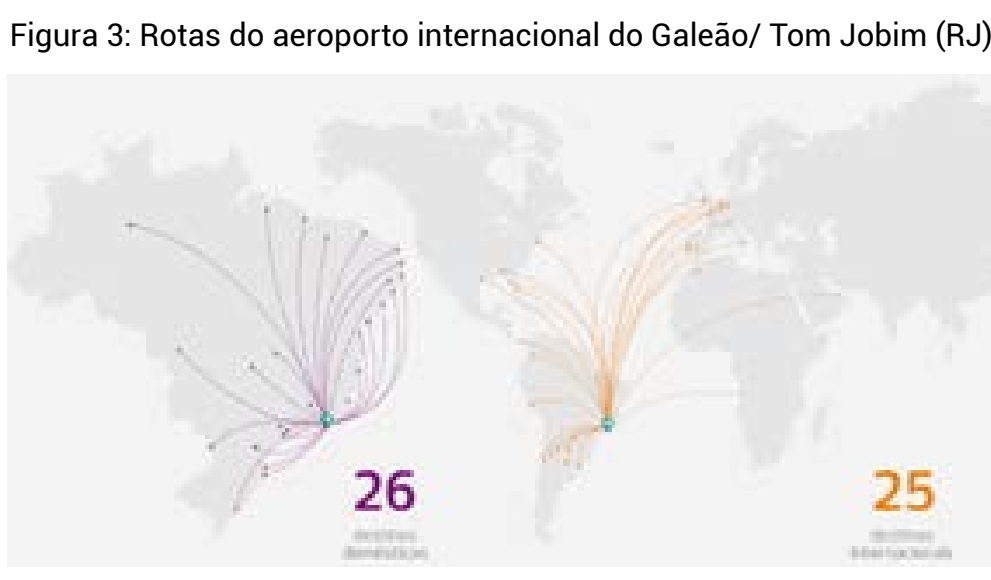

Fonte: Aeroporto RioGaleão (Acesso em 08/04/20)

\section{c) Fortaleza e Manaus, dois pontos fora da curva}

A súbita aceleração da trajetória da pandemia em Fortaleza e Manaus surpreendeu as autoridades de saúde brasileiras, o que obriga a investigar as particularidades regionais de cada uma dessas capitais e suas respectivas regiões metropolitanas e áreas de influência. Em comum, há o fato de que ambas são hubs aéreos recentes para viajantes das regiões Norte, Nordeste e Centro-Oeste alcançarem a Costa Leste dos EUA e países europeus, sem precisar de conexão em Guarulhos ou Galeão (Figura 4). Ao mesmo tempo, as novas rotas atraem suspeitos ainda eram testados com maior frequência sobretudo quando havia histórico de viagem ao exterio mas os resultados demoravam pelo menos uma semana. Um mês depois dessa primeira confirmação ol 1.394 casos notificados em 42 cidades, das Região Metropolitana, que somavam 1.277 doentes da COVID-19 (1.069 só na capital), o que representava 91\% de todo o Estado.

estrangeiros interessados em turismo ecológico e de aventura nas duas regiões, além de negócios com a Zona Franca de Manaus, cujo comércio exterior envolve mais de 20 países, dos quais metade da região Pan-amazônica além da China e África do Sul, entre outros. Por outro lado, Manaus diferencia-se da capital cearense por se também um entroncamento hidroviário tradicional para boa parte da região Amazônica, com conexões em mais de dez cidades, da fronteira com a Colômbia até Macapá, passando por Santarém, no Noroeste do Pará.
Segundo mais movimentado do Brasil, o Aeroporto Internacional Tom Jobim - rebatizado para RIOgaleão após a privatização - opera voos para 26 destinos nacionais (todos os estados do Nordeste, Sudeste Sul, mais Amazonas) e 25 internacionais, a maior para Europa e Améica Latina, alem dos EUA, ind dois países africanos (Figura 3). Segundo a empresa que o administra, tem capacidade para receber 37 milhões de passageiros por ano, mas os dados oficiais da movimentação aeroportuária mostram que pouco mais de 13.500 mil efetivamente embarcaram ou desembarcaram neste aeroporto no período de janeiro dezembro de $2019^{6}$. Em fevereiro de 2020, quando o Rio de Janeiro ainda não tinha nenhum caso confirmado de Covid-19, foram pouco mais de 1 milhão de passageiros dos quais $37 \%$ em voos internacionais.

Num desses voos estava uma mulher de 27 anos, moradora do município de Barra Mansa, no Sul 7 Dados disponiveis em: https:// www.riogaleao.com/corporativo/page/sobre-0-
riogaleao (Acesso em: 8 abr. 2020)
Figura 4 - Rotas dos aeroportos de Fortaleza e Manaus
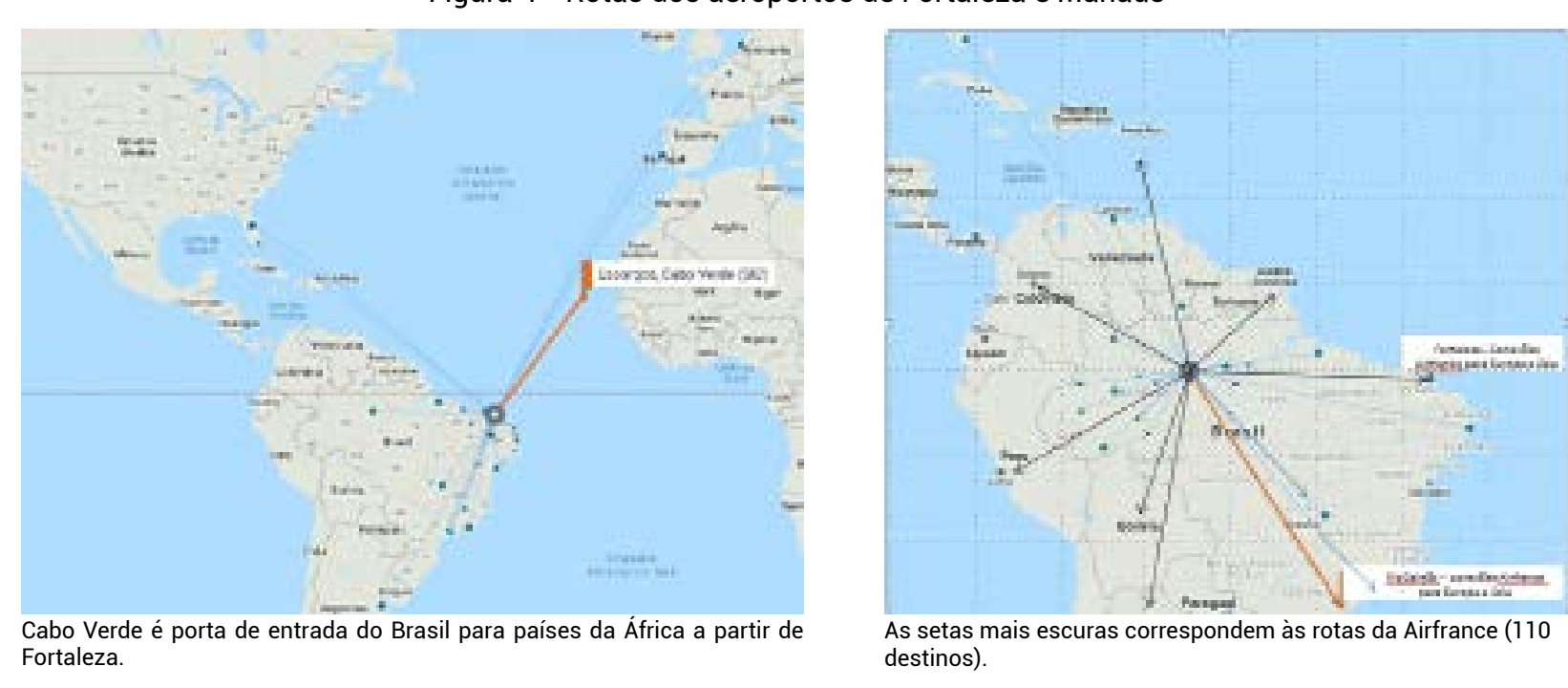
Desde que a capital cearense se tornou o destino urístico mais procurado da Região Nordeste e o quinto do País, o Aeroporto Internacional de Fortaleza assumiu também a quinta posição em número de visitantes estrangeiros, 2,26\% do total, logo atrás de Brasília $(2,6 \%)$ e Campinas (3,1\%), mas bem distante de Rio de Janeiro $(19,4 \%)$ e São Paulo $(59,7 \%)$, segundo dados da ANAC (2019, apud BARBOSA, 2020). De acordo com a Fraport $A G$, empresa alemã que administra este aeroporto desde 2017, a localização geográfica estratégica da cidade contribuiu para torná-la porta de entrada da Europa e América do Norte para o Brasil. Atualmente o aeroporto é hub aéreo da Air France-KLM/GOL e opera oito destinos internacionais: Madri, Paris, Amsterdã, Lisboa, Ilha do Sal (Cabo Verde), Miami, Buenos Aires e Caiena

Os três primeiros casos de COVID-19 em Fortaleza

(e no Estado) foram confirmados no dia 15 de março: dois homens e uma mulher da cidade que haviam voltado de viagem ao exterior. Cinco dias depois o Ceará já aparecia em $4^{\circ}$ lugar nas estatísticas da epidemia no Brasil, com 68 doentes identificados (63 na capital) e a Secretaria estadual de Saúde anunciava a primeira transmissão comunitária. Na véspera, o Boletim Epidemiológico da SES já havia divulgado que 39,1\% dos casos confirmados eram de pessoas que estiveram em outro país ou estado, ou que tinham tido contato com elas. Em 7 de abril, o Ministério da Saúde informou que Fortaleza ja apresentava a maior incidência de casos de Foporcionalmente à população, 34,7 a cad 100 mil habitantes. Doze dias depois, os 3.212 casos confirmados espalhavam-se por 102 cidades de todas as sub-regiões cearenses, dos quais quase $84 \%$ na capital.

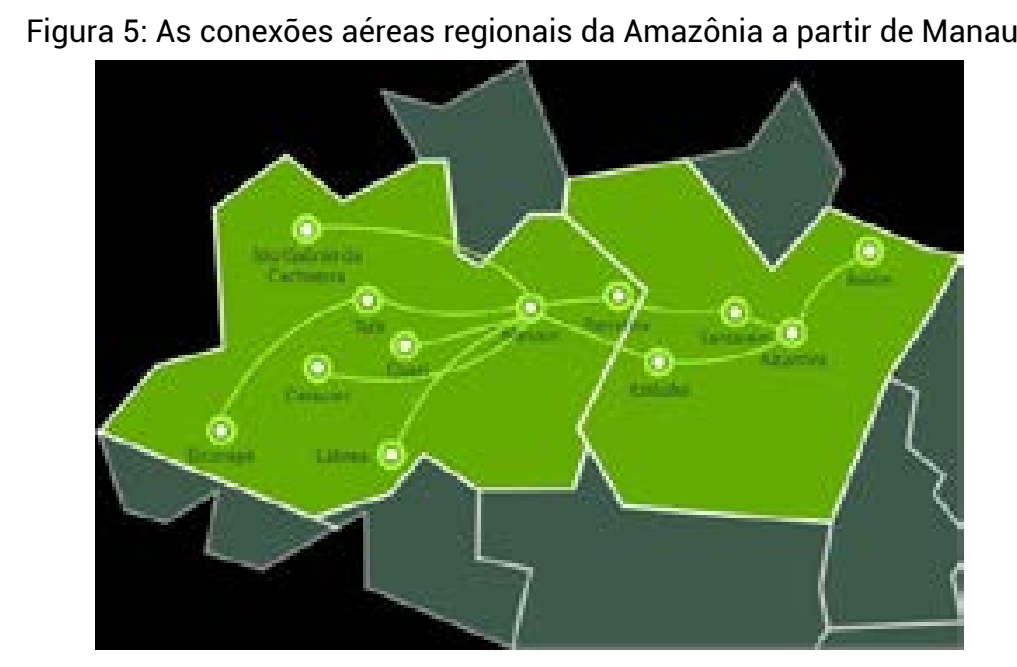

Fonte: rotas aéreas da MAP disponível em: https://voemap.combr/destinos/

Apesar de ser $017^{\circ}$ no ranking dos aeroportos brasileiros em número de passageiros pagos (dados de 2019), o Aeroporto Internacional Eduardo Gomes, em Manaus, está interligado ao país e ao exterior por meio de 134 voos operados por oito companhias aéreas, cinco delas com rotas internacionais. Azul e GOL dividem as rotas nacionais e regionais, e MAP, somente as regionais, alcançando 11 cidades da Amazônia Legal (Figura 5) 7 . A Air France apresenta uma lista de 110 cidades "de chegada" a partir de Manaus, que abrangem 54 países (incluindo todos os europeus) e cinco territórios; dos EUA, são sete cidades das costas Leste e Oeste; da China,

a capital e mais três grandes cidades (Cantão, Xanga e Hong-Kong); e no Brasil, os três principais hubs dos voos internacionais (BSB, GRU e GIG). Ou seja, por essas rotas da aérea francesa, Manaus está mais conectado com o mundo do que Guarulhos e Galeão, o que ajuda a explicar que $81 \%$ dos casos confirmados da COVID- 19 no Amazonas, até 19/04/2020, tenham ocorrido na capital contra $19 \%$ em outros 24 municípios.

Contudo, o transporte fluvial ainda é predominante nos fluxos de pessoas e cargas na Amazônia, envolvendo rotas que atravessam as bacias de nove grandes rios $d$ região ${ }^{8}$ cujo pinc (Figura 6). Por isso, essa modalidade foi alvo de uma guerra judicial envolvendo medidas de contenção do coronavírus. A

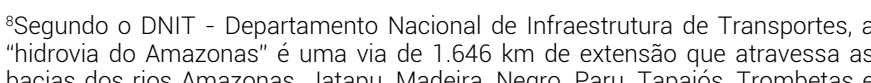

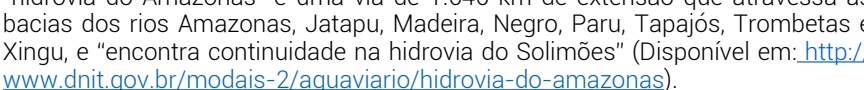

Figura 6 - Trajetos norte e sul da Hidrovia Solimões-Amazonas

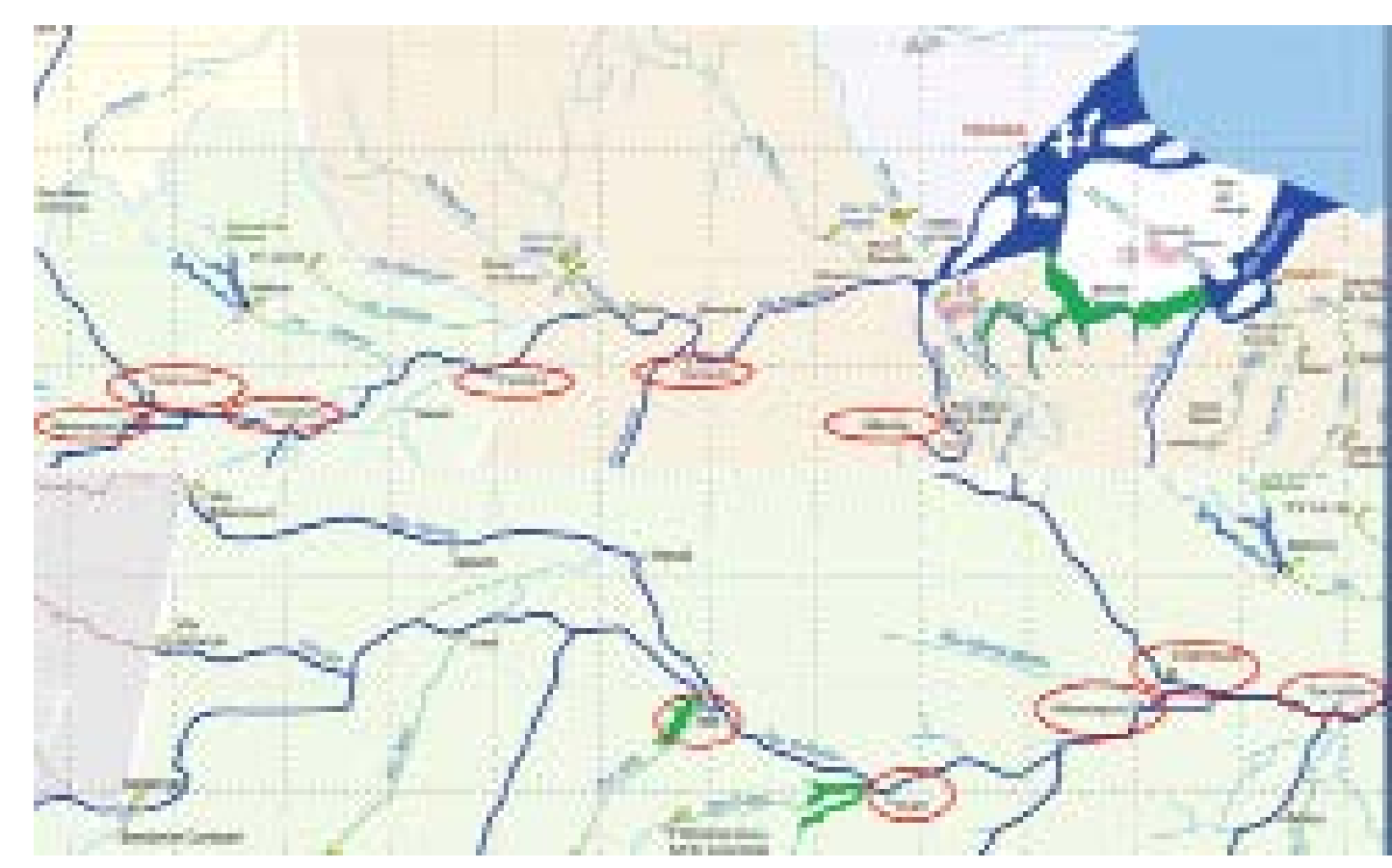

Fonte: DNIT - Departamento Nacional de Infraestrutura de Transportes (2015), com destaque de algumas cidades identificadas na Tabela 4.

controvérsia foi entre um decreto estadual que proibia "os serviços de transporte fluvial de passageiros, operados por embarcações de pequeno, médio ou grande porte, de qualquer natureza, dentro dos limites territoriais do Estado do Amazonas", e a Advocacia Geral da União (AGU), segundo a qual "a vedação ao transporte de pessoas (...), além de flagrantemente inconstitucional, trará prejuízos à população mais carente do interior, que ficará isolada e desabastecida" (BOSELLI, 2020).

Os dados comparativos compilados na Tabela 4 indicam que o governo estadual estava certo, pelo menos em relação aos riscos de contaminação. Em 7 de abril, o Amazonas tinha 636 casos em 13 cidades. Doze dias depois já eram 2.044 casos no dobro de cidades, das quais Manacapuru, a mais próxima da capital (Figura 6), passou de 42 para 201 casos confirmados (quase cinco vezes mais), seguida de longe por Itacoatiara, com 29. Chama a atenção o fato de que, das sete cidades do Estado conectadas a Manaus por tráfego aéreo, apenas duas não tinham casos confirmados até 19 de abril: Eirunepé, próxima à fronteira do Acre; e São Gabriel da Cachoeira, na fronteira com a Colômbia, próximo a Roraima. Já entre as oito principais cidades amazonenses interligadas à capital por rotas fluviais, apenas Barcelos não tinha registro do vírus até então, enquanto das quatro cidades paraenses com ligações aereas e fluviais a Manaus, apenas Oriximiná ainda não havia sido contaminada.
Os fluxos domésticos do Distrito Federal e de Minas Gerais

exterio o forte dos aeroportos de Brasília e Belo Horizonte são as conexões nacionais para todas as regiões do país Em janeiro de 2020, mais de 1.500 mil passageiros transitaram pelosvoosnacionais do Aeroporto deBrasília o maior hub aéreo doméstico, segundo a Inframerica que administra o negócio desde a privatização, em 2012. Em fevereiro, já sob o impacto das notícias sobre o coronavírus na China e na Europa, foram cerca de 300 mil passageiros a menos nos voos domésticos, mas ainda na casa de um milhão. Desses, os passageiros de voos internacionais oscilaram entre de 69 mil e 56 mil nos primeiros dois meses do ano. Já o Aeroporto Internacional de Belo Horizonte teve um fluxo de pouco mais de um milhão de passageiros domésticos, contra cerca de 50 mil em rotas internacionais em janeiro, números que em fevereiro caíram para as casas de 825 mil e 31 mil, respectivamente, segundo o Consórcio BH Airport/ Infraero.

Uma mulher residente em Brasília e recém-chegada de uma viagem ao Reino Unido foi o primeiro caso da COVID-19 no Distrito Federal (DF), confirmado pela Secretaria de Saúde local em 5 de março. Nessa mesma semana, quando a comitiva presidencial voltou de uma viagem oficial aos Estados Unidos, os casos confirmados começaram a subir progressivamente, 
fetando ministros, secretários e outros funcionários do governo federal, além de senadores e deputados. Em 16 de março eram 14 casos confirmados; quinze dias depois já eram 312.

O impacto dessa aceleração exponencial motivou a população do DF a obter o segundo melhor índice de adesão ao isolamento social entre as capitais brasileiras (62\%), no início de abril, apesar dos esforços em contrário do presidente da República. 0 resultado foi a redução do

ritmo da contaminação ${ }^{9}$, atestada na Tabela 3.0 último boletim epidemiológico da Secretaria de Saúde do DF emitido antes do fechamento deste ensaio (19/04) incidência de casos de COVID-19 por 100 mil habitantes, na qual a Região Administrativa do Lago Sul aparece como a de maior incidência (Figura 7). É nessa área que vive parte da classe alta brasiliense e também onde fica o Aeroporto de Brasília.
Figura 7 - Distribuição geográfica de incidência de casos no DF

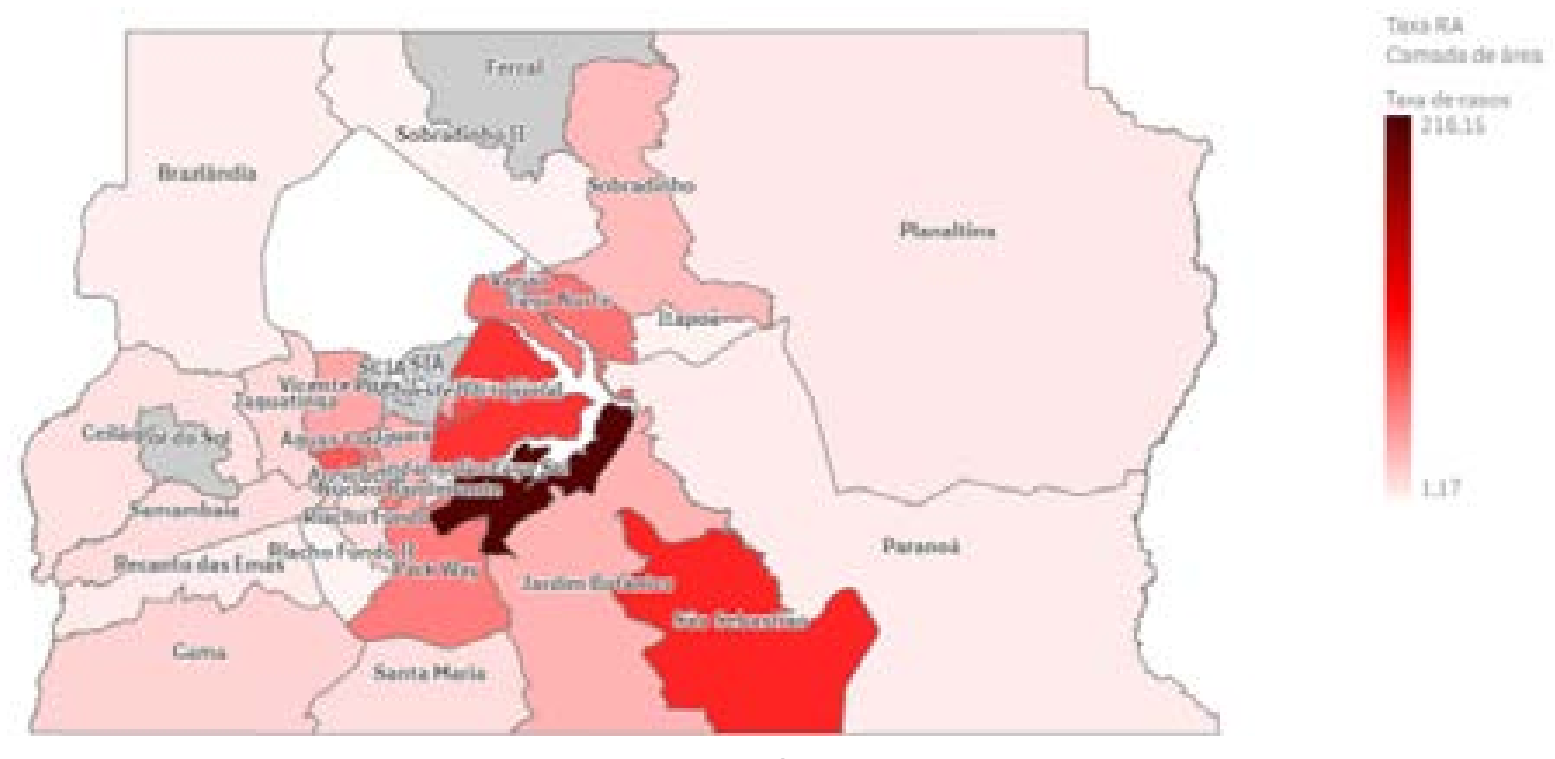

Fonte: Boletim Epidemiológico do GDF de 19/04/2020

Em Minas Gerais, ao contrário do que ocorreu na maioria dos estados brasileiros, os quatro primeiros casos confirmados do novo coronavírus, na primeira quinzena de março, não ocorreram na capital e sim em cidades do interior, bem distantes umas das outras (Figura 8) e com históricos de viagem variados. Uma mulher de Divinópolis ( $155 \mathrm{~km}$ a oeste de Belo Horizonte), que esteve na Itália; uma residente de Ipatinga $(212 \mathrm{~km}$ a leste de $\mathrm{BH}$ ) que visitou Israel; uma pessoa de Patrocínio (no Sudoeste de Minas, a $426 \mathrm{~km}$ da capital) que também esteve na Itália; e um morador de Juiz de Fora (a 262 km a sudeste de $\mathrm{BH}$ ) que voltou dos EUA.

Figura 8 - Distribuição geográfica dos primeiros casos confirmados em MG

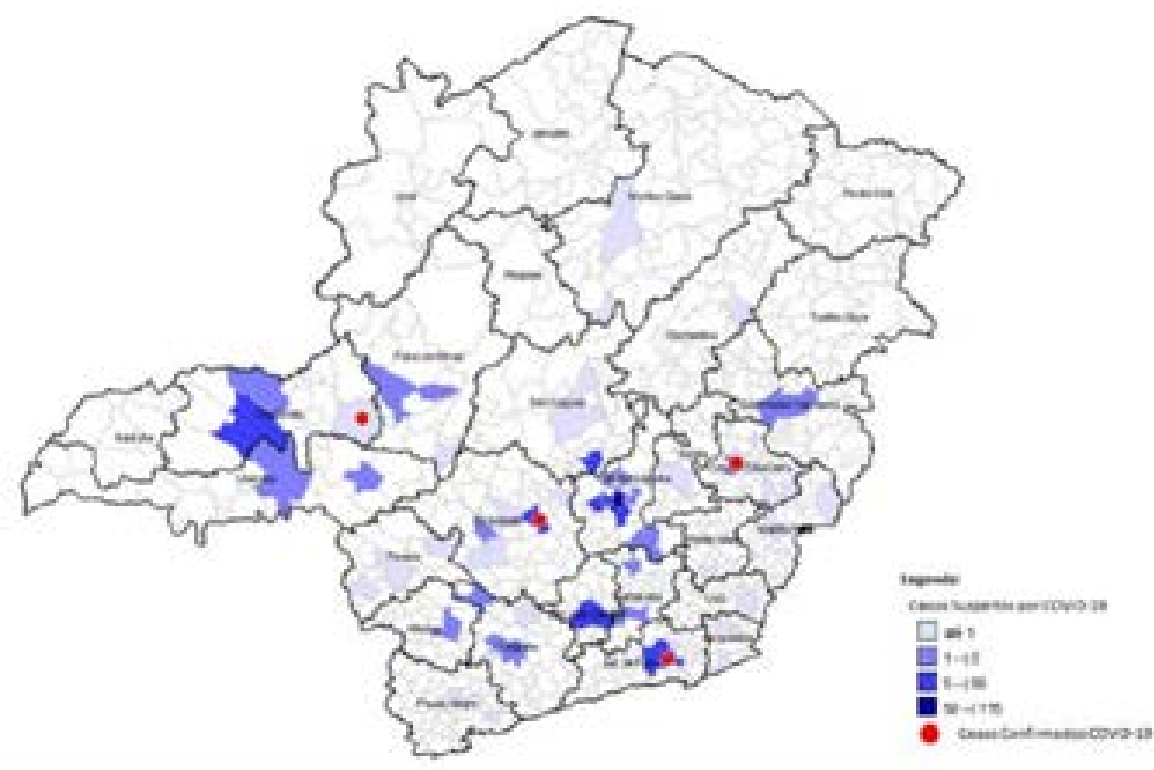

Fonte: Boletim Informativo Coronavirus da SES de MG (14/03/2020).

Essa distribuição espacial inicial da contaminação em Minas Gerais influenciou na forma como a doença se disseminou, acumulando-se na metade meridional do som isso, Belo Horizonte concentrou um percentual de casos bem menor que o das demais capitais, oscilando entre $49 \%$ e $39 \%$ do total, até 19 de abril. No restante do Estado, os focos de contaminação seguiram rotas variadas, conforme os fluxos domésticos. Juiz de Fora, com o maior número de casos fora da capital (93), Nova Lima, área de alto poder aquisitivo, registrava a maior contaminação da Região Metropolitana de BH (45 casos), seguida de Divinopolis (36) e do polo industrial de Contagem (34).

\section{e) Acidentes de percurso nas rotas de Salvador e Recife}

Apesar de possurem rotas aereas domésticas e internacionais semelhantes ${ }^{10}$ e movimentação de passageiros equiparável (entre 700 e 800 mil por mês, em média)"11, os aeroportos de Salvador e Recife causaram impactos diferentes na propagação da pandemia em seus respectivos estados. Na Bahia, os aeroportos regionais de Feira de Santana, Ilhéus Porto Seguro tiveram papel coadjuvante na entrada de pessoas contaminadas, vindas do exterior e de outros estados com a entrada pelo aeroporto da capital (incluindo voos de Fernando de Noronha) e um navio cargueiro com casos na Região Metropolitana de Recife

$\mathrm{Na}$ Bahia, o vírus fez um percurso inicial semelhante ao de Minas Gerais: começou pelo interior, alastrou-se pelo Sul da Bahia e depois se disseminou pela faixa leste do territorio baiano, afetando 92 cidades até 19 de abril. 0 primeiro caso confirmado no Estado fo também o primeiro do Nordeste: o de uma mulher de Feira de Santana (a $109 \mathrm{~km}$ de Salvador) que esteve em Milão e Roma e manifestou os sintomas da infecção após retornar ao Brasil, em 25 de fevereiro. 0 caso só foi oficializado no dia 6 de março, quando o Brasil tinha apenas nove casos em outros cinco estados.
"Até março de 2020, o aeroporto de Salvador possuía rotas para todas as capitails e Brasilia, e de Feira de Santana e Porto Seguro: o de Recife cobria todas essas

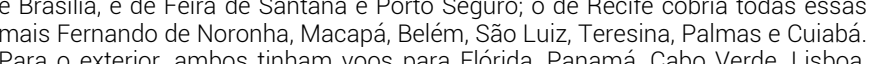
Para o exterior, ambos tinham voos para Flórida, Panamá, Cabo Verde, Lisboa,
Madrie Buenos Aires (conforme mapas disponiveis em <https://www.kayak.com.
"Cálculo baseado nos dados fornecidos pelas empresas que administram os dois
aeroportos, a francesa VINCI Airports, que controla o de Salvador desde 2018 , e a

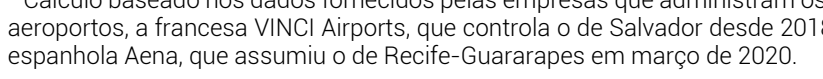


Figura 9 - Distribuição espacial da Covid-19 na Bahia

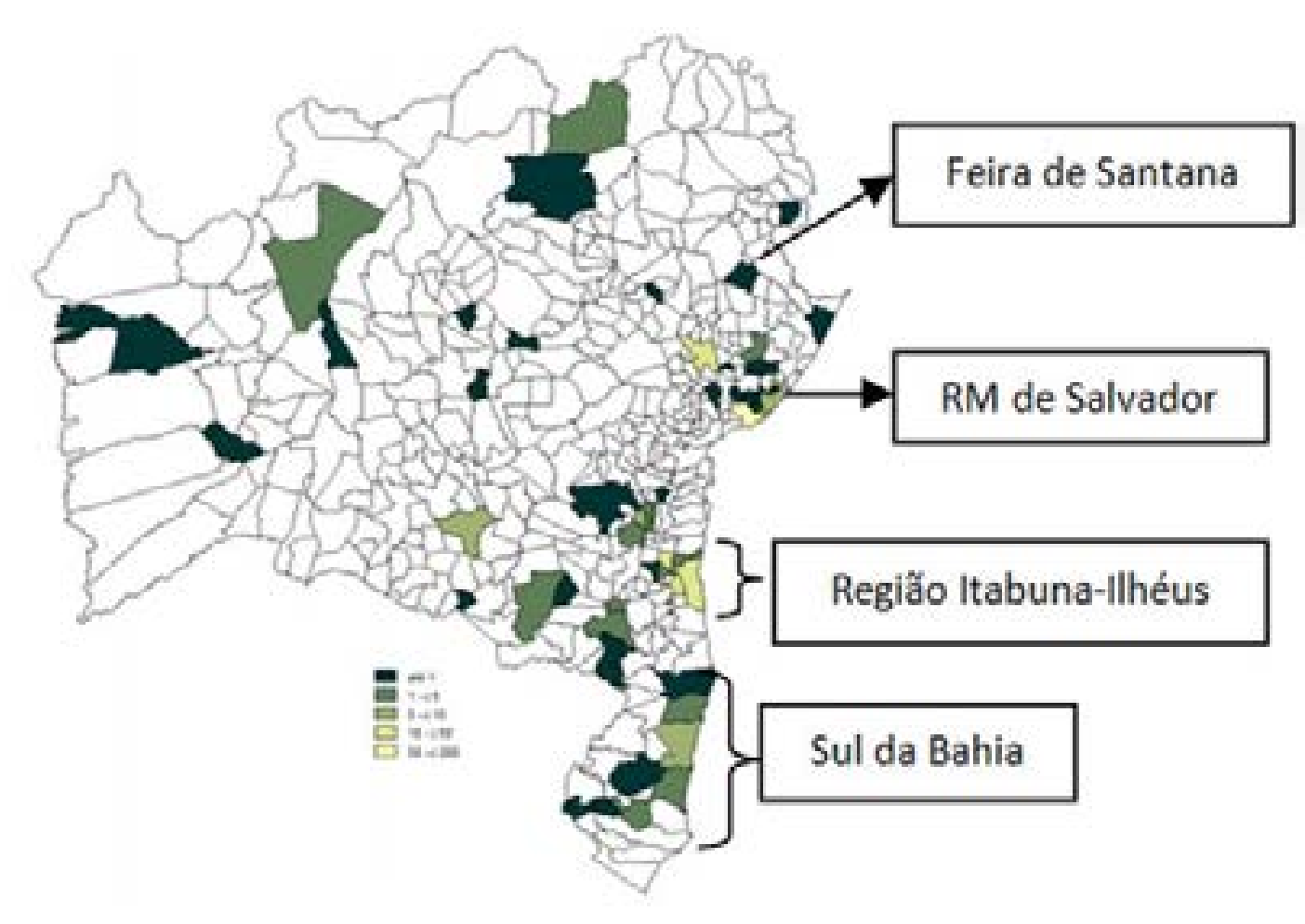

Fonte: Elaboração própria sobre mapa do Boletim Epidemiológico Covid-19 BA nº 12 (07/04/2020).

O monitoramento diário da pandemia pela Coordenação de Informação e Investigação Estratégica de Vigilância em Saúde (Cievs) permitiu identificar quatro polos de transmissão local na Bahia (Figura 9) ${ }^{12}$. Salvador mais sete dos 12 municípios da Região Metropolitana, que acumularam $66 \%$ dos 462 casos confirmados no Estado até $07 / 04$, com destaque para Lauro de Freitas (30) e Camaçari (22), na área industrial petroquímica. Feira de Santana que é município-sede da segunda Região Metropo forte entreposto comercial, teve 59 casos diagnosticados até essa data, dos quais cinco de pessoas que residem em outros estados.Na região geográfica imediata de Iheus-Itabuna, cinco municipios somaram 37 casos até
7 de abril, dos quais 18 em llhéus e 12 em Itabuna. Mas o corona não afetou Itacaré onde aconteceu um badalado casamento de celebridades, no qual pelo menos quatro dos 500 convidados apresentavam sintomas da COVID-19, entreosquaisumjovempaulistanoqueadmitiu ter contraído o vírus nos Estados Unidos. 0 quarto pólo é o Sul da Bahia, liderado por Porto Seguro, com 13 casos (dos quais pelo menos dois oriundos do casamento de Itacare), e mais seis municípios próximos, que somam 14. Porto Seguro também foi alvo de controvérsia envolvendo um empresário paulista que organizou uma festa em Trancoso após receber diagnóstico positivo de COVID-19, e que pode ter sido responsável por alguns desses 27 casos da região ${ }^{13}$

Figura 10 - Casos confirmados em Pernambuco (até 19/04/19)

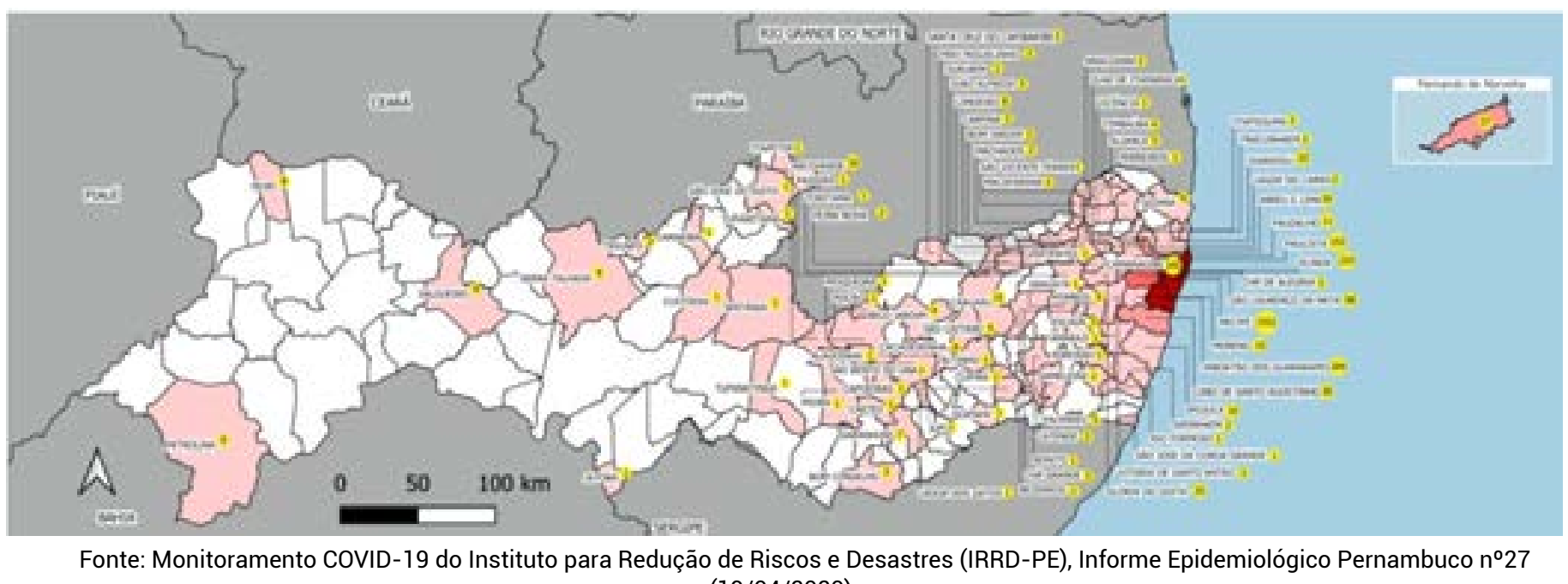
(19/04/2020).

Embora divulgados tardiamente, em 12 de março, os dois primeiros casos de COVID-19 confirmados pela Secretaria de Saúde de Pernambuco - um casal de idosos que voltou de Roma em 29 de fevereiro e foi internado cinco dias depois - é semelhante a outros que abriram as estalist que estava acompanhando notificações suspeitas de pessoas com histórico de passagem por países como Espanha, Portugal, Estados Unidos (em voos diretos para Recife), França, Inglaterra, Alemanha, Suíça, Holanda, Emirados Ara local do novo a empregada doméstica do casal de idosos, de 47 anos, que teve contato direto com os dois. Um caso semelhante ao que acabou vitimando outra trabalhadora doméstica, no Rio de Janeiro.

A primeira ocorrência de transmissão comunitária anos, moradora da capital, que se somou a outros 18 já confirmados. Diferentemente da Bahia e de Minas, a trajetória da disseminação do coronavírus no Estado permaneceu $88 \%$ concentrada em Recife (146 casos) e sua Região Metropolitana (mais 51 em sete municípios) até $0223^{\circ}$ caso, em 6 de abril. Os demais ocorreram em outros nove municípios (quatro do Agreste, dois do em outros nove municípios (quatro do Agreste, dois do Sertão), além do Arquipélago de Fernando de Noronha, nessa conta não entraram os passageiros contaminados em um navio cargueiro que aportou em Recife em 12 de março. Até 19 de abril, mais da metade do território pernambucano ainda não havia sido alcançada pelo novo coronavírus (Figura 10). f) Fluxos regionais no Paraná e no Rio Grande do Sul

Enquanto Porto Alegre mantém fluxos aéreos internacionais edomésticossemelhantesaos deSalvado e Recife, o Aeroporto de Curitiba, apesar de também ostentar o "internacional" no nome opera principalmente rotas domésticas, interligando dez cidades do próprio Estado e as outras duas capitais da Região Sul, além de conexões com Campinas, Guarulhos e Brasília, e de três
capitais do Mercosul. Em comum, os dois estados têm a operação de aeroportos regionais situados em pontos estratégicos dos respectivos territórios, marcados por divisões geográficas fortemente influenciadas por fluxos migratórios em seus processos de ocupação colonização e desenvolvimento. Como diferencia importante há o fato de que o Paraná possui sete outras regiões metropolitanas (RMs) além da capital, enquanto o RS se restringe à de Porto Alegre.

Quando a Secretaria de Saúde do Rio Grande do Sul anunciou a confirmação laboratorial do primeiro caso da COVID-19 do estado, em 10 de março, o Brasil já tinha 34 contaminados pelo novo coronavírus, dos quais $19 \mathrm{em}$ São Paulo, oito no Rio de Janeiro e dois na Bahia. Tratavase de um homem de 60 anos, residente em Campo Bom (na RM de Porto Alegre), que havia retornado de Milão em 23 de fevereiro e manifestou os sintomas seis dias depois. Menos de um mês depois, em 7 de abril, o Rio Grande do Sul acumulava 554 casos em 71 municípios, dos quais $63 \%$ concentrados na capital (271) e cidades da Região Metropolitana (78) como Nova Hamburgo, Gravataí, Canoas, São Leopoldo, Viamão, entre outras. Como mostra a Figura 11 , o rastro de contaminação subiu a Região da Serra (de imigração italiana), notadamente Caxias do Sul e Bento Gonçalves, seguindo em direção a Passo Fundo e Erexim, ao norte. Casos isolados se 
espalharam pelas demais regiões gaúchas, exceto Bajé, no extremo Sul, que em 19 de abril já tinha 29 casos diagnosticados.

À semelhança da Bahia, no Rio Grande do Sul há certa correspondência entre cidades que sediam aeroportos regionais com voos regulares e o maior número de contaminados locais. Segundo o Departamento Aeroportuário do governo gaúcho, terminais públicos como Caxias do Sul e Passo Fundo apresentaram aumento de $20 \%$ no número de passageiros no primeiro

semestre de 2019, em comparação ao mesmo período de 2018. 0 início das operações da rota Caxias do SulGuarulhos (SP), em 2018, e apontado como o principa GOV 2019), facilitando o trânsito internacional do descendentes de italianos, por exemplo. Já o Aeroporto Internacional Comandante Gustavo Kraemer, de Bage, administrado pela Infraero, opera com aeronaves particulares, táxis aéreos e jatos executivos, usados principalmente por empresários do agronegócio.

Figura 11 - Rastros da contaminação a partir de Curitiba e Porto Alegre
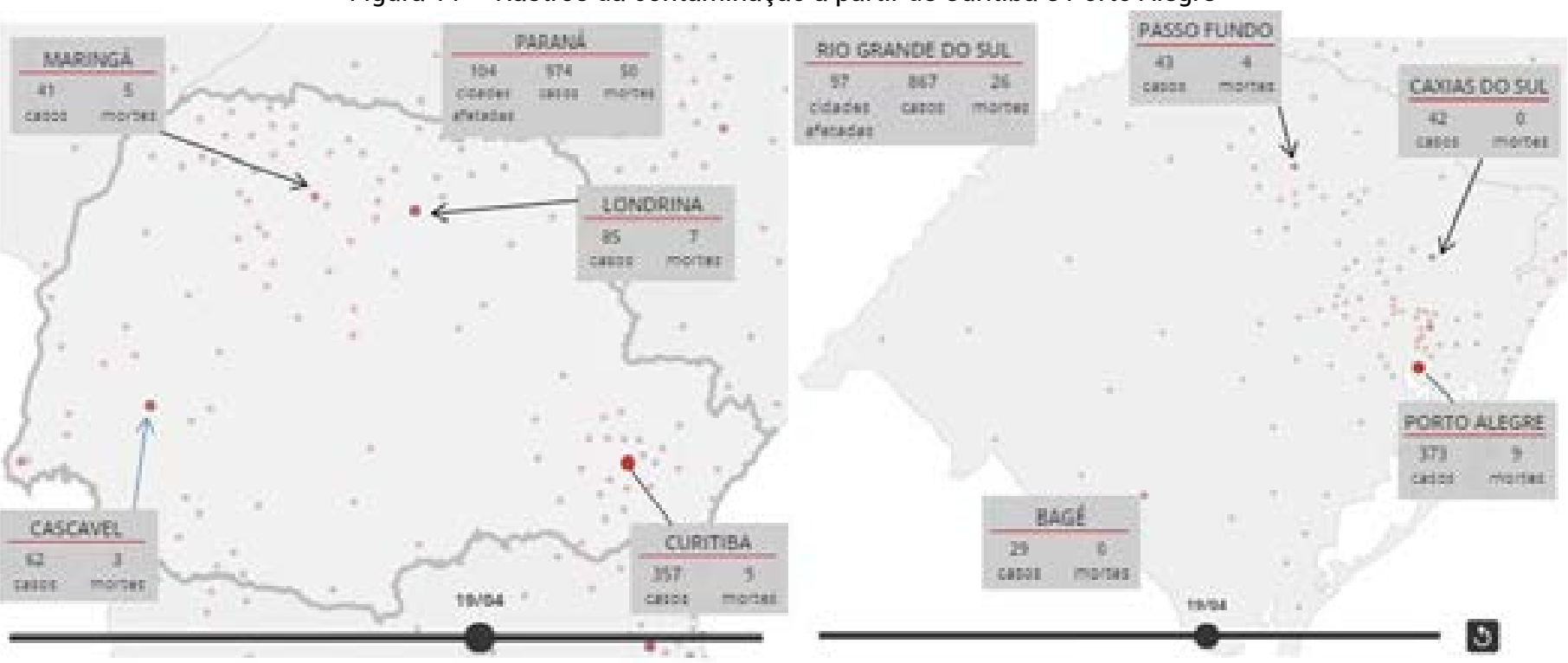

Fonte: Elaboração própria sobre mapa do Painel da COVID19 do portal G1.
Com um processo de testagem mais lento, a Secretaria de Saúde do Paraná anunciou os seis primeiros casos de COVID- 19 de uma vez, no dia 12 de março, dos quais uma mulher residente em Cianorte, na Região Noroeste, que esteve nos Emirados Árabes, e os demais de Curitiba, com históricos de passagens recentes por Espanha, Portugal, Holanda e Itália (Informe COVID-19 SES-PR, 17/03/2020). Cinco dias depois, outros seis casos importados foram registrados em quatro cidades além da capital - Cianorte (mais um), Campo Largo, Pinhais e Londrina -, num movimento de dispersão territorial de contaminação diferenciado das demais unidades da federação.

No $7^{\circ}$ dia de abril o Paraná já acumulava 511 diagnósticos positivos da doença, distribuídos por 68 municípios de praticamente todas as suas regiões regiões metropolitanas: a de Curitiba, com 284 casos (dos geográficas, porém com maior concentração em cinco quais 11 em São José dos Pinhais, onde fica o aeroporto da capital, e 36 em outros quatro municípios), número equivalente a $55,5 \%$ do total de registros da doença no Estado; a de Londrina, com 61 na cidade-sede, mais oito em Arapongas; a de Maringá, com 27 casos na própria

Naquele momento, duas outras cidades paranaenses não situadas em RMs chamavam a atenção pela concentração de casos: Foz do Iguaçu, área de intenso fluxotransfronteira,com 27; eCianorte,municípiodepouco mais de 82 mil habitantes que viu seus dois primeiro casos importados local. Contudo, quase $87 \%$ das cidades paranaense afetadas pelo coronavírus até a primeira semana de abril tinham entre um e seis casos confirmados, 0 que tanto a variedade de portas de entrada do vírus importado, quanto fluxos no território de pessoas contaminadas (geralmente assintomáticas). cidade; e Campo Mourão, com 16 (G1 PR, 09/04/2020).
Outro indicador dessa mobilidade do vírus é que 12 dos casos diagnosticados até então eram de pessoas residentes em outros estados. Tal movimentação pode do Paraná, que tem experimentado tráfego intenso. Todas as cidades que tinham mais de seis casos de coronavírus na primeira quinzena de abril são dotadas de aeroportos com voos regulares. Em outubro de 2019, o governo paranaense lançou o programa Voe Paraná, com a meta de interligar aeroportos regionais de 12 municípios ao Afonso Pena, que iriam se somar a outros sete já contemplados com voos regulares a partir do erminal de São José dos Pinhais, na RM de Curitiba. Destes, seis municípios já tinham os maiores índices de contaminação pela COVID-19 na primeira semana de abril: Arapongas, Campo Mourão, Cascavel, Cianorte, Foz do Iguaçu, Londrina e Maringá
Onde tudo começou: de Wuhan para o mundo, via Itália

Embora a origem exata desta versão mais recente da familia de coronavirus ainda seja controversa, ninguém contesta que o marco zero da pandemia é a cidade chinesa de Wuhan, situada a $1.152 \mathrm{~km}$ ao sul da capita Pequim, e a $839 \mathrm{~km}$ a oeste de Xangai, a maior cidade da China e centro financeiro e comercial global. Mas como se explica que o vírus possa ter se espalhado tão rapidamente, não só pela cidade, mas por todos os cantos do mundo? A resposta pode estar no perfi socioconomico ena configuração geográfica de Wuhan com estinados 11 millões de habitantes, dotada de polos universitário e econômico pelos quais transitam muitos estrangeiros (BBC/G1, 23/01/20).
Figura 12 - Os fluxos de hospedeiros do vírus a partir de Wuhan

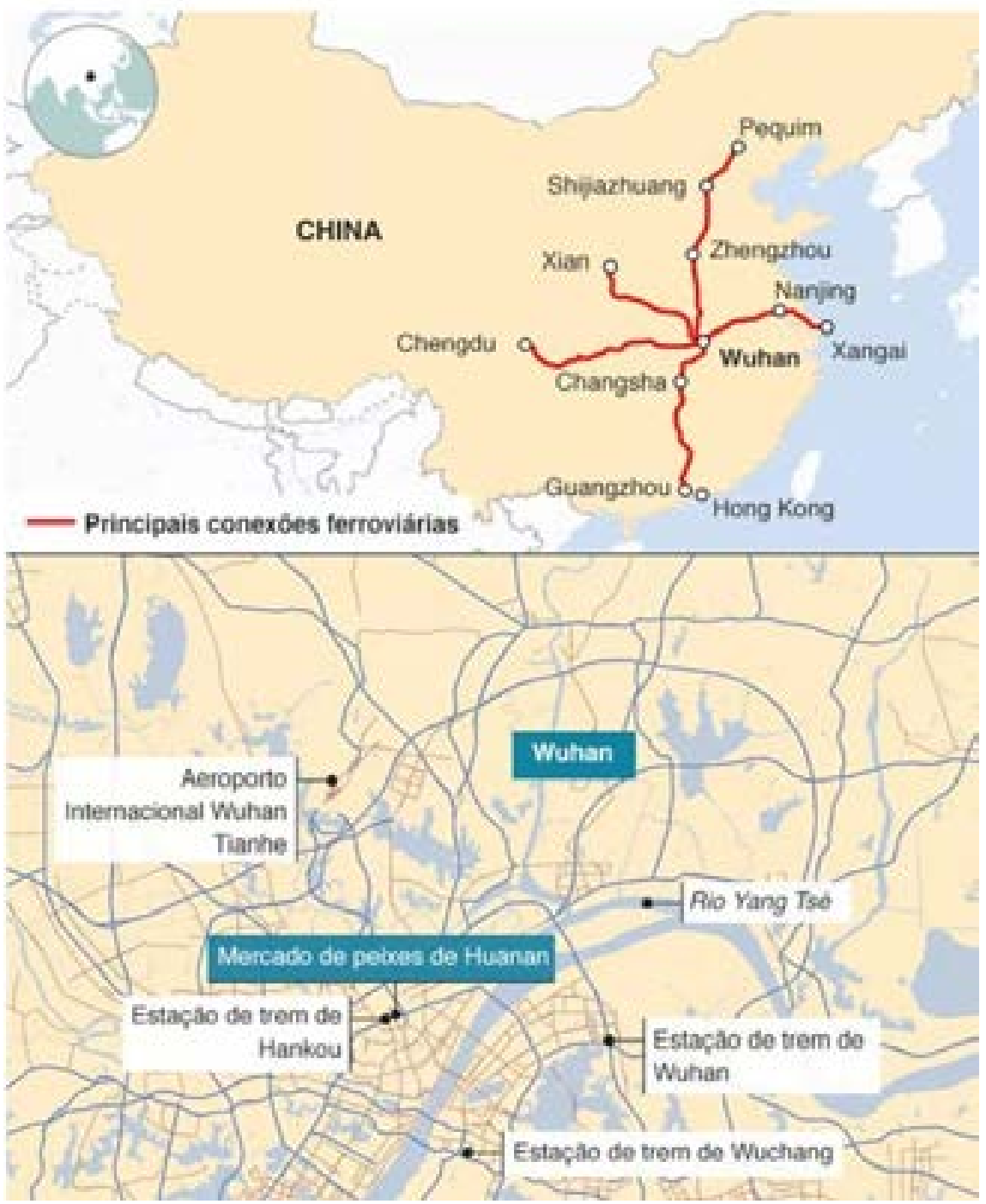

Fonte: Arte/BBC publicada na reportagem BBC/G 
Wuhan é também um entroncamento ferroviário (Figura 12) para cinco regiões da China, com terminais em Pequim, Xangai, Hong-Kong, entre outros menos conhecidos, e um hub de viagens internacionais, Londres, Paris, Dubai e Nova York. Sua geografia também favorece a circulação de pessoas por vias fluviais, como explica reportagem da BBC/G1: "Construída no curso intermediário do rio Yang Tsé - que, com quase 6,4 mil quilômetros, é o maior rio da Asia e o terceiro do mundo - também tem um importante porto, com navios que se conectam a Xangai, no Leste, ou a Chongqing, no Oeste." E Wuhan ainda "serve como porta de entrada para as Três Gargantas, uma região turística e sede da enorme hidrelétrica homônima". (...) "Em resumo: o vírus se espalhou assim porque muitas pessoas entram e saem

0 que a matéria não questiona é como um país tão longe da China como a Itália tornou-se rapidamente o novo epicentro da epidemia, superando quase todos os seus vizinhos asiáticos? Trata-se de questão importante para o Brasil, já que os supostos "pacientes zero" de vários estados passaram por Milão ou Roma antes de retornarem ao país. A Itália tornou-se um aliado estratégico da China ao se tornar o primeiro país do G-7 a aderir à Belt and Road Initiative (BRI), uma proposta de negócios multilaterais e transterritoriais lançada ao mundo pela China em 2013 (FALLON, 2020).

No início de janeiro deste ano, quando o novo coronavírus já estava circulando, a Itália assinou um memorando de entendimentos com a China, comprometendo-se a ampliar suas rotas aéreas para expandir o fluxo de turismo entre os dois países. No mesmo mês a quantidade de voos entre ambos triplicou, tornando a Itália o país europeu com mais conexões aereas com a China. Para Praveen Duddu, da revista Pharmaceutical Technology (online), o alto número de casos de COVID-19 na Itália pode ser explicado por essa rápida expansão do tráfego aéreo entre os dois países, que coincidiu com o período de emergência do novo coronavirus em Wuhan e outras localidades chinesas.

Mas outros analistas consideram mais factível que a contaminação tenha sido iniciada entre os milhares de trabalhadores "informais" chineses que contribuem para tornar cada vez mais famosas as marcas de roupas e acessórios "Made in Italy". Acusações nesse sentido se intensificaram no mês de março, à medida que mais pessoas adoeciam no país, e geraram um novo tipo de xenofobia, como revelaram reportagens do The American Spectator (20/04/20) e do The Guardian (25/04/20), entre outros. Segundo The Guardian, estimase que haja mais de 300 mil chineses residentes na Itália atualmente, formando a terceira maior comunidade de estrangeiros no país. A maioria trabalha de modo ilegal e em condições precárias, e foi levada para a Itália po empreendedoreschinesesqueinvestiramem segmentos da luxuosa indústria da moda italiana. Mais da metade deles vive em cidades do Norte, como Milão, justamente onde a COVID-19 mais se expandiu, em função de uma decisão equivocada do governo da Lombardia acerca do isolamento social.

Em 30 de janeiro, as autoridades de saúde italianas reportaram dois casos positivos da COVID-19 em turistas chineses, e em 53 dias o país já somava o maior número de infectados e de mortos pelo novo coronavírus fora da Ásia. Em seguida, muitos países começaram a notificar "casos importados" de viajantes procedentes da Itália ou que tiveram contato com italianos durante viagem à Europa (DUDDU, 2020) incluindo o Brasil, como atestam os primeiros casos registrados em diferentes estados.

\section{Vírus chega de avião e pega a estrada}

Depois de atingir os centros capitalistas do Hemisfério Norte, o novo coronavírus partiu para as periferias do mundo, dos países e das cidades, como indicam os mapas que vêm sendo produzidos por diversas fontes desde fevereiro deste ano. No caso do Brasil, em 27 de fevereiro, apenas o estado de São Paulo (em vermelho na Figura 13) tinha um caso confirmado. Doze estados (em azul) tinham somente registros de casos suspeitos (e) ainda não haviam recebido notificações do novo coronavírus. Os mapas seguintes mostram como a epidemia foi se expandindo do litoral para o interior, à exceção do Amazonas, devido à convergência de fluxos aéreos e fluviais de/para Manaus, como já visto, que rapidamente fez o estado alcançar a mesma faixa de contaminação dos estados com maior conexão com o exterior

De Manaus, o SARS-Cov-2 alastrou-se rapidamente pelos outros municípios da região metropolitana, mas causando maior estrago em Manacapuru, por onde transita uma grande população flutuante, como explicou

Figura 13 - Evolução das notificações de casos da Covid-19 no Brasil
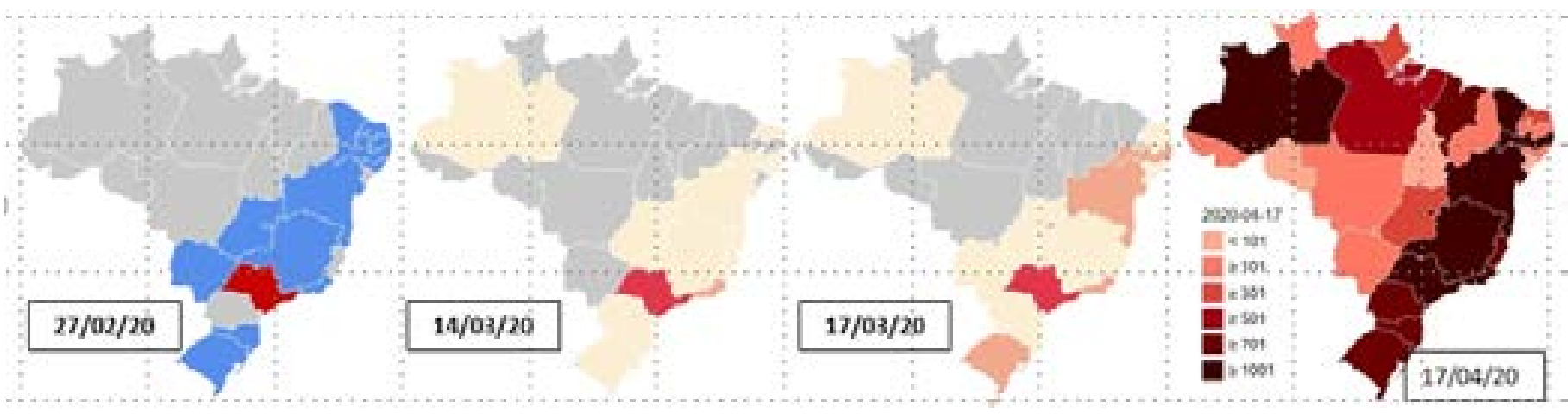
seguem escala de quantidade de casos confirmados.

Fonte: Elaboração própria com mapas da Wikimedia Commons - CovID-19 Outbreak Cases in Brazil.

não foi diferente (...). Aqui passam pessoas de oito municípios do entorno da nossa cidade. Circula muita gente, o que leva o vírus mais para dentro" (MADEIRO, 22/04/2020). Como a cidade possuía então apenas três ventiladores mecânicos, que só serviam para estabilizar pacientes em estado grave durante um processo de transferência para um hospital com UTI, os portadores para pressionar ainda mais o já saturado sistema de saúde de Manaus.

Em Pernambuco, desde que começaram a monitorar os casos confirmados de COVID-19 por locais de residência, pesquisadores do Instituto para Redução de Riscos e Desastres (IRRD-PE) observaram o aumento do número de casos nos municípios da Zona da Mata e do Agreste Pernambucano, principalmente aqueles que são atravessados pela BR-232 ou têm acesso a ela. Em reportagem publicada pela BBC Brasil (MACHADO, 18/04/20), o pesquisador Jones Albuquerque afirmou que a rota do coronavírus pelo interior pernambucano segue uma lógica econômica, social e logística.

"As primeiras infecções surgiram no Recife, no início de março, em bairros de classe média alta, como Boa Viagem e Jaqueira", que persistem como os mais afetados em números absolutos. "Depois, o vírus se espalhou para áreas mais pobres e municípios da região metropolitana", provavelmente por meio de pessoas que trabalham em bairros ricos e moram na periferia. $\mathrm{E}$ em seguida pegou a estrada rumo às pequenas e médias cidades do Agreste Pernambucano, como Arcoverde e Caruaru.

A rodovia federal que dá acesso a essa região tem 552 quilômetros de extensão e vai da capital à cidade de Parnamirim, no Sertão. Contudo, como mostra o mapa da Figura 10, mais da metade do território estadual ainda não havia sido afetada pelo vírus até 19 de abril e apenas cinco municípios do Sertão e do São Francisco Pernambucano já tinham casos registrados. Destes, três possuem aeroportos: o de Petrolina, com voos regulares de duas empresas aéreas nacionais, e os de Salgueiro e Serra Talhada para atendimento a demandas privadas locais e regionais.

\section{Em São Paulo, doença de rico, morte de pobre}

Os mapas de casos confirmados e de óbitos registrados por bairros da cidade de São Paulo (Figur 14) espelham bem as desigualdades sociais que a pandemia está desnudando. Nove dos dez bairros com mais de 150 casos confirmados, situados entre as zonas Oeste e Sul da cidade (as de maior poder aquisitivo) estão entre os que registram as menores quantidades de óbitos (abaixo de 21). Por outro lado, os com mais mortes (acima de 25) fazem parte das zonas Norte e Leste, que concentram a população de mais baixa renda da cidade. De um lado, potenciais viajantes internacionais, do outro, os que atravessam a cidade para trabalhar. Dois fluxos complementares para a disseminação da COVID-19. Um exemplo marcante desse contraste geossocial foi relatado pelo G1 São Paulo (RODRIGUES et al, 18/04/2020). 0 bairro do Morumbi, na Zona Sul, é o que concentrava o maior número de casos confirmados da doença, 297, dos quais sete pessoas morreram, de acordo com o boletim epidemiológico divulgado pela Secretaria Municipal de Saúde na véspera. Já Brasilândia, na Zona Norte, era o bairro paulistano com o maior número de mortes confirmadas ou suspeitas por coronavírus, 54 , o que representava $60 \%$ dos 89 casos confirmados da doença na localidade até essa data. 
Tabela 4 - Cidade de São Paulo: casos confirmados x óbitos por local de residência

\begin{tabular}{|l|l|l|l|}
\hline $\begin{array}{l}\text { Cidades nas rotas } \\
\text { aéreas }\end{array}$ & Casos em 19/04 & $\begin{array}{l}\text { Cidades nas rotas } \\
\text { fluviais }\end{array}$ & Casos em 19/04 \\
\hline Manaus & 1.664 & Barcelos & 00 \\
\hline S. Gabriel da Cachoeira & 00 & Manacapuru & 201 \\
\hline Eirunepé & 00 & Itacoatiara & 29 \\
\hline Coari & $\mathbf{0 2}$ & Coari & $\mathbf{0 2}$ \\
\hline Tefé & $\mathbf{0 5}$ & Tefé & $\mathbf{0 5}$ \\
\hline Carauari & 01 & São Paulo de Olivença & 11 \\
\hline Lábrea & 02 & Santo Antonio do lça* & 11 \\
\hline Parintins & $\mathbf{1 5}$ & Parintins & $\mathbf{1 5}$ \\
\hline Santarém (PA) & $\mathbf{1 7}$ & Santarém (PA) & $\mathbf{1 7}$ \\
\hline Altamira (PA) & 03 & Oriximiná (PA) & 00 \\
\hline Itaituba (PA) & $\mathbf{0 5}$ & Itaituba (PA) & $\mathbf{0 5}$ \\
\hline & & &
\end{tabular}

Fonte: elaboração própria a partir de dados do Painel Coronavírus do G1/ Bem Estar (07/04/20).

Uma semana antes, o bairro havia registrado 33 mortes, oque significaum aumento de $63 \%$. Estecontraste se reproduz também na densidade populacional: 4.119 habitantes por $\mathrm{km}^{2}$ no Morumbi (incluindo a comunidade de Paraisópolis) contra 12.615 habitantes $/ \mathrm{km}^{2} \mathrm{em}$ Brasilândia. Mas a proporção de leitos hospitalares disponiveis para cada cem mil habitantes e inversa: são 14,54 no Morumbi e 0,011 em Brasilândia, segundo o Mapa da Desigualdade em São Paulo ${ }^{14}$. A dialética entre fixos e fluxos.

\section{Para que servem os mapas de dados?}

Identificar a difusão de doenças no tempo e no espaço é uma das vertentes das pesquisas da geografia no campo da saúde, assim como informar o público sobre as ocorrências territorialmente diferenciadas dessa difusão é uma das tarefas das geografias da comunicação. Como observou Guimarães (2006, p.253), "as técnicas cartográficas utilizadas pela geografia médica permitem mapear os padrões de distribuição espacial das doenças, bem como a localização dos equipamentos médicos e os fluxos e deslocamentos espaciais resultantes da busca pela saúde"

Nesse sentido, os mapas mais complexos sobre a pandemia de COVID-19 disponíveis online vêm progressivamente incorporando outras variáveis de dados além do número de casos e de mortes, como a taxa de incidência por 100 mil habitantes, índice de mortalidade por casos confirmados, taxas de testagem e de hospitalização, entre outras possibilidades. Mas

à medida que o número de casos ultrapassa a casa dos milhares, torna-se fundamental para os gestore públicos identificar mais precisamente os lugares de maior concentração de casos, justamente para poder dimensionar as demandas por atendimento, que são locais. Daí o surgimento, sobretudo a partir de abril de 2020, de mapas municipais sobre o estado pandemia.

Pioneiro na divulgação de dados municipais sobre a propagação do novo coronavírus no Brasil, o DataRio vem agregando novas variáveis sobre os casos confirmados na cidade do Rio de Janeiro, de modo a permitir uma avaliação abrangente da complexidade desta pandemia. $\mathrm{Na}$ última versão consultada para este ensaio, além dos dados do dia, o Painel Rio COVID-19 incluía uma linha do tempo com a evolução de casos confirmados recuperados, hospitalizações, óbitos e projeção de casos. Além disso, passou a apresentar duas versões do mapa da cidade: uma assinalando a distribuição dos casos pelo territó nos bairros da Zona Sul e na Barra da Tijuca; outra discriminando a quantidade desses casos pelas Áreas de Planejamento em Saúde (APs) da Prefeitura.

Mas, diferente de São Paulo, não foi possíve estabelecer contrastes geossociais entre os números de casos confirmados e de mortes. Primeiro porque enquanto em São Paulo alguns bairros tinham mais de 50 mortes e vários ultrapassavam a casa dos 30 no Rio apenas seis bairros estavam no topo da lista de óbitos, com entre 10 e 18 (neste último caso, soment Copacabana, que tem a maior população idosa do município). Segundo, porque o Rio passou, há algun anos, por uma reforma urbana que atribuiu status de bairro a comunidades antes consideradas favelas $e$ que estão espalhadas por todas as zonas da cidade. Vidigal e Rocinha, por exemplo, integram a mesma AP de Saúde que os demais bairros da Zona Sul (onde residem pessoas das classes média e alta), enquanto os Complexos do Alemão e da Maré estão junto com os bairros da Leopoldina e llha do Governador (classe média baixa). Nessa lógica, Paraisópolis, por exemplo, seria um bairro vizinho ao Morumbi e não um enclave de pobreza na Zona Sul, como acontece em São Paulo.

Com isso, o Rio tem diversos fluxos simultâneos entres suas periferias e o "centro", representado pelos 17 bairros da Zona Sul mais a Barra da Tijuca, a parte "nobre" da Zona Oeste, onde foram registrados os primeiros casos do novo coronavírus importados do exterior. Dos mais de 3.500 casos confirmados em 19 de abril no Rio, cerca de $35 \%$ estavam internados em hospitais públicos, dos quais um terço na rede municipal e o restante na rede do SUS. Mas não havia dados sobre hospitalizações na rede privada, o que permitiria inferir o percentual de casos em isolamento doméstico.

\section{Considerações finais para seguir adiante}

A ideia de produzir este ensaio surgiu em um momento do mês de março de 2020 em que a divulgação diária de novos casos suspeitos, confirmados e fatais da COVID-19, aliada à falta de informação sobre os modos de contaminação pelo vírus, deixava as pessoas perplexas, especialmente jornalistas, atônitos com a velocidade das "novidades", e pesquisadores da área de saúde, instados a dar respostas rápidas a um fenômeno desconhecido e traiçoeiro. Naquele mar de números e dramas, uma pergunta inquietava: como falar em "reduzir a curva" da epidemia "no Brasil" quando os próprios números indicavam uma disparidade enorme entre algumas cidades e o restante de seus próprios estados, e entre estes e os demais recortes do território brasileiro? E qual a pertinência de comparar os dados nacionais com os de países como a Itália, que é pouco menor que o Maranhão, ou com a Espanha, que cabe dentro de Minas e da Bahia, estes pouco menores que a França?

Desdequemeinteresseipelaaplicaçãodopensamento geográfico aos fenômenos e sistemas da comunicação e da informação, tenho me dedicado a fazer exercícios sobre as diferenciações dos recortes regionais a partir de diferentes variáveis, tendo como principal referência o legado de Milton Santos. Neste último, aqui apresentado, foi possível constatar como um fenômeno global como a pandemia de COVID-19 ganha novos sentidos quando observado a partir das suas manifestações e narrativas locais e regionais. Este ensaio, baseado estritamente em dados públicos e informações divulgadas po diversos tipos de midia, no Brasil e pelo mundo, procurou indicar que o monitoramento dos fluxos de pessoas fundamental para o conhecimento do modus operand do vírus SARS-Cov-2 e para a contenção da doença que ele provoca.

Nesse contexto, tanto as secretarias estaduais de saúde, com seus boletins epidemiológicos diários, quanto a mídia regional, com seu olhar endógeno sobre fatos e personagens da pandemia, foram fundamentais para se chegar a detalhes que os meios ditos nacionais raramente alcançam. Por outro lado, portais de notícias nacionalmente capilarizados como o UOL (do Grupo Folha) e o G1 (da Rede Globo) - este usufruindo das informações geradas pelas emissoras afiliadas têm exercido papel importante como agregadores de dados e histórias relacionadas às vivências e formas de enfrentamento do vírus em todo o País. Veículos internacionais (inclusive alguns especializados) também ajudaram a rastrear as cadeias de contágio pelo mundo e a entender suas particularidades, como as ligações da Itália com a China.

No Brasil, algumas iniciativas de monitoramento de dados locais sobre a COVID-19 estão em andamento envolvendo pesquisadores e instituições que podem subsidiargestores dapandemianos processosdecisórios sobre as melhores formas de contenção da disseminação do vírus, conforme a sua densidade e fluidez em cada território - das pequenas cidades metropolitanas, passando pelos recortes sub-regionais dos estados. A circulação dessas informações, se revela algumas coincidências nada casuais em termos de precariedade dos sistemas e comportamentos das populações periféricas, aponta também diferenciações espaciais que merecem aprofundamento.

0 conhecimento e o controle dos fluxos são fundamentais também para a boa governança dos fixos - no caso, as estruturas de saúde e todo o seu conteúdotécnico-científico-informacional (profissionais de saúde, instalações, aparelhagem, insumos, sistemas de informação e comunicação interna e externa) - que também são desigualmente distribuídos pelos territórios tanto em termos quantitativos quanto qualitativos. $E$ não apenas no Brasil, como esta pandemia revelou ao desnudar o estado precário em que se encontram os sistemas de saúde pública mundo afora. 
Referências

AEN PR. Informe COVID-19. Sem transmissão comunitária, Paraná tem 12 casos de coronavírus. Agência de Notícias do Paraná, 17/03/2020. Disponivel em: <http://www.aen.pr.gov.br/modules/noticias/article.php?storyid=106159\&tit=Sem-transmissaocomunitaria-Parana-tem-12-casos-de-coronavirus $>$. Acesso em: 7 abr. 2020

AEN PR. Nove voos marcam estreia do programa Voe Paraná. Agência de Notícias do Paraná, 18/10/2019. Disponivel em: <http:// www.aen.pr.gov.br/modules/noticias/article.php?storyid=104254\&tit=Nove-voos-marcam-estreia-do-programa-Voe-Parana> Acesso em: 10 abr. 2020

AEN PR. Saúde confirma seis casos de coronavírus no Paraná. Agência de Notícias do Paraná, 12/03/2020. Disponível em: <http:// www.aen.pr.gov.br/modules/noticias/article.php?storyid=106078\&tit=Saude-confirma-seis-casos-de-coronavirus-no-Parana> Acesso em: 14 mar. 2020.

ANAC. Anuário Estatístico da ANAC 2018. Rio de Janeiro: ANAC, 2018. Disponível em: <http://portal.cgna.gov.br/files/uploads/ anuario_estatistico/anuario_estatistico_2018.pdf> Acesso em: 7 abr. 2020.

AREDES, Airton; SILVEIRA, Márcio Rogério. Abordagens sobre as noções de circulação, transporte aéreo e turismo na geografia tradicional: algumas reflexões. Formação (Online), v. 26, n. 49, p. 37-55, 2019. Disponível em: <https://revista.fct.unesp.br/index.php/ formacao/article/view/6339/0>. Acesso em: 7 abr. 2020

BARBOSA, Vitória. Saiba quais destinos internacionais têm voos direto de Fortaleza. Tribuna do Ceará, 13/01/2020. Disponível em: <https://tribunadoceara.com.br/diversao/turismo/saiba-quais-destinos-internacionais-tem-voos-direto-de-fortaleza/>.Acessoem 10 abr. 2020

BBC/G1. Coronavírus: como é Wuhan, a cidade chinesa onde surgiu a epidemia de coronavírus e que foi isolada. Portal G1, Ciência e Saúde. 23/01/2020. Disponivel em: <https://g1.globo.com/ciencia-e-saude/noticia/2020/01/23/coronavirus-como-e-wuhan-acidade-chinesa-onde-surgiu-a-epidemia-de-coronavirus-e-que-foi-isolada.ghtml>. Acesso em: 10 abr. 2020.

BOSELLI, André. Desencontro das águas: transporte fluvial de passageiros volta a ser suspenso no Amazonas. Consultor Jurídico, 30/03/2020.Disponívelem:<https://www.conjur.com.br/2020-mar-30/transporte-fluvial-passageiros-volta-suspenso-am>. Acesso em: 7 abr. 2020

CATRACA LIVRE. Investigado homem com coronavírus que foi ao casamento de irmã de Pugliesi. Catraca Livre, 23/03/2020 Disponívelem:<https://catracalivre.com.br/cidadania/investigado-homem-com-coronavirus-que-foi-em-casamento-de-irma-depugliesi/>. Acesso em: 10 abr. 2020

CEARÁ, Secretaria Estadual de Saúde. Boletim Epidemiológico no 18, 19/03/2020. Disponivel em: <https://www.saude.ce.gov.br/ wp-content/uploads/sites/9/2018/06/boletim_n18_COVID_19_mar_20_SM.pdf>. Acesso em: 20 mar. 2020.

DUDDU, Praveen. Coronavírus in Italy: outbreak, measures and impact. Pharmaceutical Technology, March 23, 2020. <https://www. pharmaceutical-technology.com/features/covid-19-italy-coronavirus-deaths-measures-airports-tourism/>.Acessoem:7abr.2020 FALLON, Theresa. China, Italy, and Coronavirus: Geopolitics and Propaganda. The Diplomat, March 20, 2020. Disponível em: <https:// thediplomat.com/2020/03/china-italy-and-coronavirus-geopolitics-and-propaganda/>. Acesso em: 7 abr. 2020

G1 BA. Governador determina que PGE abra processo contra paciente que veio contaminado com coronavírus para sul da BA. G1 Bahia,Salvador, 17/03/2020. Disponivelem:<https://g1.globo.com/ba/bahia/noticia/2020/03/17/governador-determina-que-pgeabra-processo-contra-paciente-que-veio-contaminado-com-coronavirus-para-sul-da-ba.ghtml>. Acesso em: 10 abr. 2020

G1 PR. Paraná chega a 621 casos de coronavirus e confirma mais sete mortes pela doença, diz Sesa. Paraná RPC, Curitiba 09/04/2020. Disponivelem:<https://g1.globo.com/pr/parana/noticia/2020/04/09/parana-chega-a-621-casos-de-coronavirus-econfirma-mais-sete-mortes-pela-doenca-diz-sesa.ghtml> Acesso em: 10 abr. 2020.

GIACOBELLI, Leandro e GUIMARÃES JR, Paulo R.. Dinâmicas de contágio. Como epidemias se espalham por um país continental? Guimarães Lab, s/d.[2020]. Disponível em: <https://guimaraeslabbr.weebly.com/voos.html>. Acesso em: 14 abr. 2020.

GUIMARÃES, Raul Borges. Saúde pública na América Latina: questões de geografia política. In: LEMOS, A.I.G.; SILVEIRA, M.L.; ARROYO, M. (orgs.). Questões territoriais na América Latina. Buenos Aires/SP. Clacso/USP, 2006. pp.249-263

IRRD-PE. Coronavírus (COVID-19): Informe Epidemiológico Pernambuco n 27. Instituto para Redução de Riscos e Desastres, 19/04/2020. Disponivel em: <https://drive.google.com/drive/folders/1SjM9e7E1hFY2EKLKRJ2PTQP4c21WH5f0>. Acesso em: 19 abr. 2020

MACHADO, Leandro. Coronavírus: a rodovia federal que 'levou' a Covid-19 para o interior de Pernambuco. BBC News Brasil, São Paulo, 18/04/20. Disponivel em: <https://www.bbc.com/portuguese/brasil-52332235>. Acesso em: 19 abr. 2020.

MADEIRO, Carlos. Sem UTI, cidade do AM líder em Covid-19 tem aglomerações e mortes em casa. Portal UOL, Coronavírus, 22/04/2020. Disponivel em: <htps://noticias.uol.com.br/saude/ultimas-noticias/redacao/2020/04/22/manacapuru-coronavirusamazonas. htm>. Acesso em: 22 abr. 2020

MCCAIN, Robert Stacy. Coronavirus: The Price of Luxury. Fashion's "Made in Italy" tag is connected to a Chinese disease. The American Spectator, 20/04/20. Disponivel em: <https://spectator.org/coronavirus-the-price-of-luxury/>. Acesso em: 20 abr. 2020 MORGADO, Andréa Vaz; PORTUGAL, Licínio da Silva; MELLO, Andréa Justino Ribeiro. Acessibilidade na Região Amazônica através do transporte hidroviário. Journal of Transport Literature, vol.7 no.2, Manaus, Apr. 2013. Disponível em: <http://www.scielo.br/pdf/jtl/ v7n2/v7n2a06.pdf>. Acesso em: 7 abr. 2020.

OBSERVATÓRIO COVID19; Grupo: Redes de Contágio \& Eduardo X. F. G. Migon. Vulnerabilidade das microrregiões do Estado de São Paulo à pandemia do novo coronavírus (SARS-CoV-2). Scielo Preprints, Versão 1, 15/04/2020. DOI: <https://doi.org/10.1590/ SciELOPreprints.49>. Acesso em: 19 abr. 2020.

OMS. Coronavirus Situation Report, n. 59. Disponivel em: <https://www.who.int/docs/default-source/coronaviruse/situationreports/20200319-sitrep-59-covid-19.pdf?sfvrsn=c3dcdef9_2>. Acesso em: 7 abr. 2020

RODRIGUES, Rodrigo; BORGES, Beatriz; FIGUEIREDO, Patrícia. Morumbi tem mais casos de coronavírus e Brasilândia mais mortes óbitos crescem 60\% em uma semana em SP. G1 SP, São Paulo, 18/04/2020. Disponivel em: <https://g1.globo.com/sp/sao-paulo/ noticia/2020/04/18/morumbi-tem-mais-casos-de-coronavirus-e-brasilandia-mais-mortes-obitos-crescem-60percent-em-umasemana-em-sp.ghtml>. Acesso em: 19 abr. 2020

RS GOV. Aeroportos regionais registram aumento na movimentação de passageiros. Governo do Estado do Rio Grande do Sul ÚltimasNotícias,30/07/2019. Disponívelem:<https://estado.rs.gov.br/aeroportos-regionais-registram-aumento-na-movimentacaode-passageiros>. Acesso em: 7 abr. 2020.

SANTOS, Milton. A natureza do espaço. Técnica e Tempo. Razão e Emoção. São Paulo: Edusp. 2014

SANTOS, Milton; SILVEIRA, María Laura. O Brasil: território e sociedade no início do século Xxi. Rio de Janeiro: Record, 2008.

SÃO PAULO, Secretaria Municipal de Saúde. Boletim Semanal COVID-19, 17/04/20 (versão atualizada). Disponível em: <https:// www.prefeitura.sp.gov.br/cidade/secretarias/upload/saude/PMSP_SMS_COVID19_Boletim\%20Semanal_20200417_atualizado pdf>. Acesso em: 19 abr. 2020

SATRIANO, Nicolás. Mulher de Barra Mansa é o $1^{\circ}$ caso confirmado do novo coronavírus no estado do RJ. Rio de Janeiro: G1 Rio Riode Janeiro,05/03/2020. Disponívelem:<https://g1.globo.com/rj/rio-de-janeiro/noticia/2020/03/05/rj-confirma-primeiro-casodo-novo-coronavirus-diz-secretaria.ghtml>. Acesso em: 6 mar. 2020

SILVA JUNIOR, Roberto França da. Circulação, epistemologia e a constituição de um ramo da ciência geográfica. Boletim Campineiro de Geografia, v.2, nº3, 2012. p.389-417. Disponivel em: <http://agbcampinas.com.br/bcg/index.php/boletim-campineiro/article/ view/78>. Acesso em: 6 mar. 2020.

STEFANO, Fabiane. Por coronavírus, 57\% da população brasileira está em isolamento. Revista Exame (online), São Paulo, 01/04/2020. Disponivelem:<https://exame.abril.com.br/brasil/por-coronavirus-57-da-populacao-brasileira-esta-em-isolamento/>.Acessoem:6 abr. 2020.

THE GUARDIAN. 'As if we were the disease': coronavirus brings prejudice for Italy's Chinese workers. The Guardian, International edition (online), 25/04/20. Disponivel em: <https://www.theguardian.com/global-development/2020/mar/25/as-if-we-were-thedisease-coronavirus-brings-prejudice-for-italys-chinese-workers/>. Acesso em: 25 abr. 2020 


\section{Fontes online:}

\section{Aeroportos}

Aeroporto de Brasília <https://www.bsb.aero/br/o-aeroporto/dados-operacionais/estatisticas/>

Aeroporto de Recife-Guararapes <https://www.aenabrasil.com.br/pt/aeroportos/aeroporto-internacional-do-recife-guararapesgilberto-freyre/index.html>

Aeroporto de Salvador <https://salvador-airport.com.br/>

Aeroporto Internacional Comandante Gustavo Kraemer (Bagé) <https://www4.infraero.gov.br/aeroportos/aeroporto-internacionalde-bage-comandante-gustavo-kraemer/sobre-o-aeroporto/historico/>

Aeroporto Internacional Eduardo Gomes (Manaus)<https://www4.infraero.gov.br/aeroportos/aeroporto-internacional-de-manauseduardo-gomes/sobre-o-aeroporto/caracteristicas/>

BH Airport/ Infraero <https://site.bh-airport.com.br/SitePages/pt/publicacoes/estatisticas.aspx>

Fraport AG (Fortaleza) <https://fortaleza-airport.com.br/>

GRU Airport (São Paulo-Guraulhos) <https://www.gru.com.br/>

RIOgaleao <https://www.riogaleao.com>

AirFrance - Partidas de Manaus: listagem disponível em <https://www.airfrance.com.br/voos/partida-manaus>

ANAC - Painel de Indicadores do Transporte Aéreo 2018 <https://www.anac.gov.br/assuntos/dados-e-estatisticas/mercado-detransporte-aereo/painel-de-indicadores-do-transporte-aereo>

Boletim Epidemiológico Covid-19 BA <http:\www.saude.ba.gov.br\wp-content \uploads\2020\04\boletimEpidemiogicoCovid-19>

Boletins Epidemiológicos COVID-19 da Secretaria de Saúde do Governo do Estado do Ceará - <https://www.saude.ce.gov.br/ download/boletins/>

Boletins Epidemiológicos Coronavírus da Secretaria de Estado de Saúde de MG <https://saude.mg.gov.br/coronavirus/boletim> DNIT - Hidrovia do Solimões-Amazonas. <http://www.dnit.gov.br/hidrovias/hidrovias-interiores/hidrovia-do-solimoes-amazonas/ hidrovia-solimoes-amazonas>

Informativos Epidemiológicos do GDF <http://www.saude.df.gov.br/informes-epidemiologicos/>

Informe Epidemiológico Covid-19 SES-PR <http://www.saude.pr.gov.br/modules/conteudo/conteudo.php?conteudo=3507>

Observatório COVID-19 BR <https://covid19br.github.io/>

Painel Casos de coronavírus no Brasil e no mundo. Portal G1. <https://especiais.g1.globo.com/bemestar/coronavirus/mapacoronavirus/>

Panel Coronavirus Resource Center Johns Hopkins University and Medicine. <https://coronavirus.jhu.edu/map.html>

Pernambuco contra a Covid19<<https://www.pecontracoronavirus.pe.gov.br/>

Suframa <http://www.suframa.gov.br/>

Wikimedia Commons - COVID-19 Outbreak Cases in Brazil. <https://commons.wikimedia.org/wiki/File:COVID-19_Outbreak_Cases_ in_Brazil.svg> 